\title{
LA EVOLUCIÓN DE LA FORMA DE GOBIERNO EN FRANCIA: ¿UNA VÍA HACIA UN PRESIDENCIALISMO NEOPARLAMENTARIO?
}

\author{
JUAN JOSÉ RUIZ RUIZ
}




\section{SUMARIO}

I. INTRODUCCIÓN. II. EL DEBATE EN TORNO A UNA MUTACIÓN EN LA FORMA DE GOBIERNO. III. LA POSIBILIDAD DE UN CONTROL INSTITUCIONAL AL PRESIDENTE. A) El derecho de dirigir mensajes y alocuciones a las Cámaras. B) La comparecencia del Presidente en comisiones de investigación. IV. EL PROBLEMA DE LA DELIMITACIÓN DE FUNCIONES ENTRE PRESIDENTE Y PRIMER MINISTRO: LA FUNCIÓN DE GOBIERNO. V. UNA LECTURA DE LA REFORMA EN CLAVE NEOPARLAMENTARIA. VI. CONCLUSIONES. 


\title{
LA EVOLUCIÓN DE LA FORMA DE GOBIERNO EN FRANCIA: ¿UNA VÍA HACIA UN PRESIDENCIALISMO NEOPARLAMENTARIO?
}

\author{
POR \\ JUAN JOSÉ RUIZ RUIZ \\ Universidad de Jaén
}

\section{INTRODUCCIÓN}

La reforma de la Constitución Francesa (en adelante $\mathrm{CF}$ ) votada y aprobada el 21 de julio de 2008 tuvo como inspiración el réequilibrage, —reequilibrio_-, de las instituciones junto a su modernización y democratización y la concesión de nuevos derechos a la ciudadanía. De esos tres grandes ejes que han guiado la operación reformadora sólo el primero, el relativo al equilibrio institucional, cabe considerarlo como el verdadero motivo que ha impulsado esta revisión. Nuestra doctrina se ha ocupado ya especialmente de los aspectos más innovadores que esta reforma ha incorporado al texto constitucional y en lo que se refiere a los equilibrios institucionales ha prestado mayor atención a los contenidos de derecho parlamentario que con cierto espíritu reglamentista han encontrado acogida en los preceptos constitucionales ${ }^{1}$. Podría parecer además que en este aspecto, el de la denominada re-parlamentarización, esta reforma vendría a dar continuidad a una tendencia más o menos manifiesta del legislador constitucional, tal y como puede observarse del hecho que en el cómputo global de las reformas llevadas a cabo el Parlamento haya sido el directo beneficiario de la totalidad de los cam-

${ }^{1}$ Cfr. el monográfico de Cuadernos de Derecho Público, no 34-35, mayo-diciembre 2008, cuya sección notas dedica está dedicada por entero a «Reformas de la institución parlamentaria». 
bios introducidos al texto constitucional ${ }^{2}$. Sin embargo, la reforma de 2008 no puede abordarse separadamente de los cambios introducidos con el quinquenato, del que trae su causa directa y que habrían supuesto una mutación de la forma de gobierno o cuando menos un punto de inflexión. Interpretada en ese contexto la reforma impulsada por el Presidente Sarkozy ha constituido el intento para que el nuevo status institucional del Presidente derivado de la reforma del quinquenato obtuviera un reconocimiento constitucional, y en particular para adecuar el texto constitucional a un ejercicio del poder político, que se adivina monocrático tras la casi contextualidad de las elecciones presidenciales y legislativas. En pocas palabras, se trataba de dar carta de naturaleza a las nuevas condiciones que afectan a la distribución de poderes, especialmente entre Presidente y Primer Ministro, y de establecer limitaciones parlamentarias a las facultades presidenciales, ahora asimiladas a facultades primo-ministeriales en virtud de la reducción del mandato y de la precedencia de las elecciones presidenciales a las legislativas cuya celebración es casi simultánea. De ahí que esta última reforma haya sido considerada como el segundo acto del reciente proceso evolutivo que habría hecho propios alguno de los rasgos de la forma de gobierno de neo-premier, sin abandonar esencialmente los equilibrios hasta ahora existentes, actuando sobre la denominada separación temporal de poderes que afecta al plano funcional de las instituciones pero no al plano estructural. Nuestro propósito es indagar sobre estos elementos estructurales, que dificultan la adecuación de la forma de gobierno de la $\mathrm{V}$ República al modelo de gobierno neoparlamentario o de premier electivo.

La ley constitucional $\mathrm{n}^{\circ} 2008-724$ du 23 juillet 2008, de modernisation des institutions de la $\mathrm{V}^{\mathrm{e}}$ République, vino precedida de las propuestas del denominado Comité Balladur, pero no se inscribía como a veces se ha dicho en una mera operación de toilettage o mantenimiento constitucional ${ }^{3}$, sino que bien podría enmarcarse dentro de lo que ha venido en llamarse aceleración constitucional ${ }^{4}$, fenómeno que se produce cuando se intensifican las revisiones formales para adecuar las constituciones. La necesidad de una aceleración constitucional fue precisa-

2 Vid. JEAN GICQUEL, «La reparlementarisation: une perspective d'évolution», Pouvoirs, $\mathrm{n}^{\circ}$ 126 monográfico La Ve République, 2008, p. 48.

3 En efecto al decir de Francesco Palermo se asiste en los últimos años al surgimiento de una nueva función que el autor denomina «manuntenzione costituzionale» y que arranca de la necesidad de establecer nuevos mecanismos para superar la contraposición entre revisión formal y adecuaciones informales, especialmente cuando el pluralismo subyacente impide una modificación formal. Vid. FRANCESCO PALERMO, «La "manuntenzione costituzionale": alla ricerca di una funzione», en ID. (a cura di), La «manuntenzione» costituzionale, Padova, 2007, p. 8.

4 Vid. F. PALERMO, «La “manuntenzione costituzionale”...», op. cit., p. 16. 
mente uno de los aspectos centrales de las elecciones presidenciales de 2007, en las que más de la mitad de los candidatos incluían propuestas de revisión constitucional de los equilibrios institucionales. A pesar de haberse dado por «muerta» la V República ${ }^{5}$ por entender que se ha alcanzado el máximo de concentración de poder presidencial, y a pesar también del efectista debate en torno a una VI República ${ }^{6}$ interesa señalar que ninguna propuesta de los principales candidatos en la campaña de las presidenciales de 2007 abogaba por un retorno a una presidencia de república parlamentaria con régimen primo-ministerial ${ }^{7}$, sino que todo el empeño de las diferentes propuestas se ha centrado en limitar los poderes de un Presidente sometido al control de la oposición y en reequilibrar al Parlamento respecto al poder Ejecutivo ${ }^{8}$.

Las propuestas en las elecciones presidenciales de 2007 pretendieron extraer de este modo las lecciones de los cambios constitucionales y legislativos que instauraron el quinquenato (año 2000) ${ }^{9}$, que liga e iguala el mandato presidencial al de los diputados y la inversión del calendario electoral (año 2001) ${ }^{10}$, que convierte las elecciones a la Asamblea Nacional en una convocatoria accesoria y

5 Vid. MICHEL LASCOMBE, «La V république se meurt, la V République est morte», en AA.VV., Constitutions et pouvoirs. Mélanges en l'honneur de Jean Gicquel, Paris, 2008, para quien tras las últimas reformas la forma de gobierno en la Constitución de 1958 es la de un «cesarismo democrático» antes que una democracia parlamentaria o presidencial, p. 303.

${ }^{6}$ En general, sobre la posibilidad de cambiar la forma de gobierno abandonando la actual, vid. AA.VV., Demain. La Sixième République?, Centre d'Etudes et de Recherches Constitutionelles et Politiques, Toulouse, 2007. Entre todos los trabajos de este volumen, vid. en particular, GUY CARCASSONNE, «Les nécessités d'un passage à la VI İme République», pp. 107-114, para una lúcida exposición de por qué ninguna reforma en sentido primo-ministerial cambiaría el actual funcionamiento de la forma de gobierno sin renunciar a la elección directa del Presidente.

7 Así resulta para los tres grandes candidatos. Por el contrario, siete de los doce candidatos a las elecciones presidenciales de 2007, y conocidos como los «pequeños candidatos», incluían en sus programas superar las ambigüedades del modelo semipresidencial abogando por su ruptura para dar paso a una VI República. Vid. BASTIEN FRANÇOIS, «Les candidats à l'élection présidentielle et la réforme des institutions», Regards sur l'actualité, no 339, mars 2008, p. 44.

8 En parte las propuestas de la campaña presidencial de 2007 lo que habrían tratado es de desterrar la práctica institucional que conducía a la pretensión de los partidos mayoritarios de gobernar ensemble, definiendo e introduciendo los mecanismos necesarios de un estatuto de oposición para que pueda cumplir su papel de alternativa a la mayoría presidencial, algo que hasta ahora como tal no ha existido y cuya introducción en la Constitución ha sido descrita como una revolución de la cultura política existente. Vid. ANNE LEVADE, «La démocratie en mutation? Brève chronique d'une anée électorale française», en AA.VV., Constitutions et pouvoirs, op. cit., p. 337.

9 Loi constitutionnelle $\mathrm{n}^{\circ}$ 2000-964 du 2 octobre 2000 (J.O. du 3 octobre 2000).

${ }^{10}$ Loi organique $\mathrm{n}^{\circ} 2001-419$ du 15 mai 2001 modifiant la date d'expiration des pouvoirs de l'Assemblée nationale (J.O. du 16 mai 2001). 
propiciatoria de una mayoría parlamentaria presidencial. Ambas reformas suponían en efecto una acentuación en la presidencialización de la V República, y ello no tanto por convertir en marginal la posibilidad de una cohabitación, pues el couplage de mayoría presidencial y parlamentaria no representa ninguna novedad en la marcha institucional del régimen gaullista, — más bien había venido siendo la norma desde sus inicios_- , sino que el aspecto realmente innovador consistió en asociar las elecciones legislativas a las presidenciales, introduciendo de este modo un elemento estructural antes inexistente y que, aunque con todos los matices, caracteriza los sistemas de neoparlamentarismo o neopremier cuya elaboración doctrinal se debe a las propuestas de Duverger ${ }^{11}$ de los años cincuenta y a la posterior elaboración teórica de autores como Galeotti ${ }^{12}$.

En torno a la reforma de 2008 existe un cierto consenso en cuanto a que ha supuesto un paso más en la evolución iniciada en el bienio 2000-01 con la reforma del quinquenato y la inversión de elecciones ${ }^{13}$, y en cuanto a que viene a significar el inicio del fin del debate en torno a una VI República ${ }^{14}$. Sin embargo, sigue sin haber acuerdo respecto a si esta reforma acentúa el carácter hiperpresidencialista de la V República con la consolidación de una presidencia de legislatura, o si por el contrario existen elementos funcionales no muy diferentes a los de un neoparlamentarismo de investidura electiva ${ }^{15}$. Tras las últimas reformas que han afectado a los equilibrios institucionales (quinquenato, calendario electoral, y ahora limitación del mandato presidencial, discurso parlamentario del

11 Vid. MAURICE DUVERGER, Demain la République, Paris, 1958.

12 Vid. SERIO GALEOTTI, Alla ricerca della governabilità, Milano, Giuffrè, 1983.

$13 \mathrm{Vid}$. PAOLO RIDOLA, «Le istituzioni parlamentari nella revisione costituzionale francese del 2008: réiventer le Parlement?», en FULCO LANCHESTER e VINCENZO LIPPOLIS (a cura di), La V Reppublica francese nel dibattito en ella prassi in Italia, Napoli, 2009, p. 240.

${ }^{14}$ Vid. MASSIMO CAVINO, «La fine del mito della sesta repubblica», en MASSIMO CAVINO, ALFONSO DI GIOVINE, ENRICO GROSSO (a cura di), La Quinta repubblica francese dopo la reforma costituzionale del 2008, Torino, 2010, p. 30; BASTIEN FRANÇOIS, «Le rapport Balladur et l'idee d'une Vie République», Revue politique et parlementaire, octobre/décembre 2007.

${ }^{15}$ Vid. RINO CASELLA, «La V Repubblica francese nella riflessione di Serio Galeotti», en FULCO LANCHESTER e VINCENZO LIPPOLIS (a cura di), La V Reppublica francese nel dibattito..., op. cit., p. 233; RICHARD GHEVONTIAN, «La révision de la Constitution et le Président de la République: l'hyperprésidentialisation n'a pase u lieu», Revue française de droit constitutionnel, $\mathrm{n}^{\circ} 77$, janvier 2009, para el que la reforma que comentamos habría supuesto «una limitación del Presidente de la República que pierde alguno de sus poderes y ve otros más delimitados y mejor controlados. En contra, vid. MAURO VOLPI, «La forma di governo nella Costituzione Sarkozy: da La recherche du temps perdu al Gattopardo», en MASSIMO CAVINO, ALFONSO DI GIOVINE, ENRICO GROSSO (a cura di), La Quinta repubblica francese dopo la riforma costituzionale del 2008, op. cit., para el que esta reforma aunque defendible en alguno de sus aspectos, no va a «incidir de modo sustancial sobre la praxis ultrapresidencial en la gestión del poder», p. 66. 
Presidente, control parlamentario de los nombramientos) para algunos en efecto cabría hablar de una tendencia que estaría haciendo evolucionar el semipresidencialismo francés en su funcionamiento hacia esta modalidad de parlamentarismo, ya experimentada en Israel (entre los años 1996 y 2001) y a nivel infraestatal en países como Italia y para los que se ha acuñado el término de regímenes de neo-premier. La principal virtualidad de este modelo es la de desdoblar la elección del Jefe del Ejecutivo y la del Parlamento, que resultan elegidos de manera independiente pero asegurando la consecución de una mayoría de gobierno mediante la proximidad o coincidencia de las convocatorias electorales y mediante premios de mayoría a la lista del «partido presidencial». Además, en virtud de la regla aut simul stabunt aut simul cadent, se procede automáticamente a la convocatoria simultánea de elecciones parlamentarias y presidenciales para los casos de disolución anticipada o moción de censura, lo cual supone una innovación respecto a las habituales reglas del modelo de gobierno parlamentario clásico. En concreto, el recurso a las elecciones en caso de moción de censura pretende impedir que en la formación de un nuevo gobierno se interpongan los partidos de modo que aquél resulte siempre de una elección popular directa. Este es quizás el aspecto más criticado de esta forma neo-parlamentaria, no sólo por la potencial deriva bonapartista que encierra bajo la apariencia de un cierto buenismo democrático, sino también por el debilitamiento que supone para el Parlamento.

Se ha dicho que valorar la reforma de 2008 como un estadio más en una pretendida mutación, aunque sea leve, que en algún aspecto habría aproximado la evolución reciente de la V República al modelo neoparlamentario o al gobierno de neopremier, solo puede deberse a un ejercicio de escaso rigor ${ }^{16}$. Sin embargo creemos que aunque resulte cierto que en el plano estructural no sea posible afirmar que las recientes reformas permitan definir la forma de gobierno francesa tomando como referente el modelo neoparlamentario, no resulta del todo inútil examinar esta reciente evolución a partir de la finalidad que ha animado este proceso reformador. La razón es que en sus criterios inspiradores sí cabe apuntar ciertas semejanzas en la reciente evolución institucional de la V República con los fines que con el modelo neoparlamentario pretende perseguir, en particular el rendimiento mayoritario de las instituciones. Igualmente el intento ya antiguo por construir una responsiveness del Presidente mediante los procesos electorales que afectan a su partido o a determi-

${ }^{16}$ Vid. MAURO VOLPI, «La forma di governo nella Costituzione Sarkozy: da La recherche du temps perdu al Gattopardo», en MASSIMO CAVINO, ALFONSO DI GIOVINE, ENRICO GROSSO (a cura di), La Quinta repubblica francese dopo la riforma costituzionale del 2008, op. cit., p. 66.

(C) UNED. Revista de Derecho Político 
nadas decisiones a través de la consulta en referéndum, o a través de la nueva facultad de dirigir un discurso a las cámaras o su comparecencia en comisiones parlamentarias (mecanismo finalmente no incorporado al proyecto de ley de revisión constitucional), plantean la cuestión, _ similar a los regímenes parlamentarios de premier-, del desplazamiento de la responsabilidad parlamentaria hacia mecanismos electorales o hacia instrumentos en los que no es el tradicional control-sanción el que cumple la finalidad de exigencia de responsabilidad política.

Es preciso primero referirse a la cuestión de si existen elementos suficientes para determinar si puede hablarse de una mutación en la forma de gobierno que un sector doctrinal concreta en la reformas del quinquenato y del orden de convocatoria de las elecciones presidenciales y legislativas (II), para a continuación analizar los intentos llevados a cabo para encontrar fórmulas que se han estudiado hasta ahora para hallar un contrapoder a un Presidente con poderes de Premier, valorando las propuestas que a este efecto formulara el Comité Balladur (III) y que revelan el interés por equilibrar el poder presidencial desde planteamientos neoparlamentarios. Resulta además imprescindible referirse al obstáculo estructural que supone la figura del Primer Ministro para que pueda iniciarse una evolución en sentido neoparlamentario y que ha impedido siquiera residenciar la función de gobierno en el Presidente, habida cuenta que se ha excluido de la última reforma la posibilidad ni tan siquiera de incorporar parte del contenido de la regla «simul simul», previendo la dimisión presidencial para el caso de disolución anticipada de la cámara baja o, a la inversa, podía haberse contemplado la disolución automática de la Asamblea Nacional para el caso de dimisión, fallecimiento, inhabilitación o destitución del Presidente, todo lo cual no exige la desaparición de la figura del Primer Ministro (IV). A pesar de dichos obstáculos es posible explorar una vía para trazar elementos comunes de esta reciente evolución institucional con la forma de gobierno de neopremier (V), antes de elaborar una conclusión que tiene en cuenta el carácter monocrático que se ha infundido al funcionamiento institucional con las recientes reformas constitucionales, así como el carácter parlamentario que para cierto sector doctrinal sigue teniendo el régimen semipresidencial en Francia (VI).

\section{EL DEBATE EN TORNO A UNA MUTACIÓN EN LA FORMA DE GOBIERNO.}

La necesidad de reequilibrar las instituciones es un discurso que se viene repitiendo con cierta periodicidad a lo largo de toda la V República, especialmente en lo que se refiere a la institución parlamentaria y a las relaciones entre Presidente y 
Primer Ministro, aunque no es algo específico del régimen constitucional de 1958, pues desde tiempos de la III República no han cesado de denunciarse los desequilibrios del parlamentarismo francés. En todo caso, desde los inicios del actual régimen constitucional las propuestas orientadas al reequilibrio institucional se han multiplicado, bien sea en programas electorales, bien sea en declaraciones o discursos presidenciales hasta el punto de poder llenar libros enteros ${ }^{17}$. La reforma de 2008 es sin embargo la única desde 1962 que hasta el momento ha decidido afrontar el reequilibrio del Presidente frente al resto de las instituciones ${ }^{18}$.

Si la génesis del hiper-presidencialismo cabe situarla en la temprana deriva iniciada en 1962 con la reforma que introdujo el voto popular directo para elegir al Presidente, su prolongación e intensificación prosiguió con el abandono de la lectura gaullista con la que se pretendió construir una responsabilidad electoralplebiscitaria, y habría alcanzado su cénit con la reforma del quinquenato.

En concreto la reforma del quinquenato ${ }^{19}$ (junto a la precedencia de las elecciones presidenciales a las legislativas adoptada en 2001$)^{20}$ habría producido en efecto una mutación ya que convierte al Presidente en el jefe de un gobierno de legislatura con los mismos poderes de un Premier, fenómeno que ha sido descrito como acentuación en la hiperpresidencialización del régimen ${ }^{21} \mathrm{o}$ présidentialisation exacerbée ${ }^{22}$. La clave para entender esta mutación reside en el

17 Vid. DENIS BARANGER, «Le dépérissement de la pensé institutionnelle sous la V $\mathrm{V}^{\mathrm{e}}$ République», Droits, n. 44/2, 2007, p. 41.

18 El informe del Comité Vedel en 1993 dedicó una parte de sus reflexiones y propuestas a definir mejor las competencias del Poder Ejecutivo pero en ningún momento abordaba la cuestión de diseñar mejores controles. En cambio el informe del comité Balladur no sólo dedica toda la primera parte a la cuestión del control al poder Ejecutivo sino que además centra sus propuestas por primera vez en los posibles controles al Jefe del Estado, al que dedica 9 de las 18 formuladas en esa primera parte, de las cuales sólo dos se refieren a las relaciones del Presidente con el Parlamento. Sobre este aspecto, cfr. FRANCIS HAMON, «Du comité Vedel au comité Balladur. Permanence et évolution des grands thèmes du réformisme constitutionnel», Regards sur l'actualité, La documentation Française, no 339, mars 2008, pp. 33-34.

19 La valoración de la reducción del mandato presidencial a cinco años como reforzadora del la dirección presidencial contrasta con la que en etapas anteriores se ha tenido del septenato como elemento de presidencialización de la forma de gobierno. Vid. FRANÇOISE DECAUMONT, «Le quinquennat, échec d'hier, solution de demain», Revue française de science politique, no 4-5, 1984, p. 1068.

20 La relevancia del calendario electoral es tal que para devolver la autonomía al Primer Ministro frente al Presidente bastaría que las elecciones legislativas precedieran siempre y en todo caso a las presidenciales. Sin embargo sería inevitable de nuevo un régimen de cohabitación. Vid. LOÏC PHILIP, «Pour une rationalisation des pouvoirs...», op. cit., p. 425.

21 Cfr. entre otros, GEORGES VEDEL, «Cinquième République», en O. DUHAMEL, Y. MENY (dirs.), Dictionnaire constitutionnel, Paris, 1992, pp. 138-139; SERIO GALEOTTI, «Audizione al Comitato forma di governo», Nomos. Le attualità nel diritto, 1997, nº 1, p. 234.

(C) UNED. Revista de Derecho Político 
efecto arrastre que tiene ahora la elección presidencial sobre las legislativas y cuya contigüidad reproducen el esquema de una elección combinada del Presidente y el Parlamento similar a la que existe en un modelo de neopremier. De hecho, el intento que ha supuesto el quinquenato de eliminar en el futuro toda cohabitación habría revelado la voluntad del legislador constitucional de evolucionar hacia el neoparlamentarismo en lugar de en dirección hacia un sistema presidencial, habida cuenta que se ha pretendido reducir o excluir precisamente uno de los rasgos que derivan de la separación de poderes en dicho modelo como es la cohabitación entre un Ejecutivo y un Legislativo de mayorías opuestas. Así pues, comoquiera que el contrapeso de una cohabitación queda muy atenuado y dado que las elecciones legislativas han perdido buena parte de su significado autónomo, la reducción del mandato consolida a un Presidente que ejerce la función de dirección política con un gobierno de legislatura. La consecuencia elemental es que lo que se conoce como "paradoja de la irresponsabilidad» presidencial deviene mucho más pronunciada. Si la elección de una mayoría parlamentaria es una consecuencia de la elección presidencial y si además el Presidente plantea las elecciones legislativas como una convocatoria para respaldar su programa presidencial, la afinidad con el doble mecanismo electoral del modelo de neo-premier resulta evidente. En este sentido se apunta que a la reforma del quinquenato, que instituye una presidencia de legislatura, debería seguir la desaparición de la figura del Primer Ministro y la aplicación de los mecanismos parlamentarios de responsabilidad al Presidente ${ }^{23}$.

Hay quienes niegan en cambio que con el quinquenato se haya producido dicha mutación basándose en que ninguna competencia, ni presidencial ni parlamentaria, se vio afectada por ella. Así, por ejemplo, Guy Carcassonne, subraya que ningún cambio tangible se ha derivado de la adopción del quinquenato, que no ha tenido nada de innovador sobre la práctica institucional francesa. Recuerda a este respecto que la inversión del calendario, primero las presidenciales y después las legislativas, no altera ni añade competencias al Presidente, como mucho sólo reducirá la posibilidad de que éste recurra a la disolución anticipada de la Asamblea tal y como hiciera por partida doble Mitterrand nada más iniciar sus mandatos para asegurarse una mayoría afín. No puede pues decirse que esta reforma haya creado las condiciones para una hiperpresidencialización ya que los

${ }^{22}$ Vid. OLIVIER DUHAMEL, «Vers une présidentialisation des institutions?», en PASCAL PERRINEAU, Le vote de rupture, Paris, 2008, p. 275.

${ }^{23}$ Vid. MARIE CLAIRE PONTHOREAU, «L'enigma del buon governo sotto la Quinta Repubblica», en ALFONSO DI GIOVINE e ANNA MASTROMARINO, La presidenzializzazione degli esecutivi nelle democrazie contemporanee, Torino, 2007, p. 89. 
poderes son los mismos antes y después de la reforma, al igual que sus condiciones de ejercicio ${ }^{24}$.

Sin embargo, como observa Marie-Claire Ponthoreau, aun no afectando a los poderes del Presidente no se puede decir lo mismo sobre la legitimidad ${ }^{25}$ y sobre su autonomía, que se ve reducida tras el quinquenato al exigir una mayor implicación en el gobierno de legislatura ${ }^{26}$. En efecto, a diferencia de otros semipresidencialismos como el portugués, la elección presidencial se convierte en elemento estructurador de la mayoría parlamentaria y en elemento estructural de la forma de gobierno. Es estructurador de la mayoría porque supone determinar a partir de la elección presidencial su composición y es estructural en cuanto que el quinquenato ha supuesto reforzar la estructura institucional con miras a posibilitar el continuum entre mayoría electoral, mayoría parlamentaria, gobierno y cabeza del Ejecutivo que es el basamento de todos los sistemas parlamentarios mayoritarios ${ }^{27}$.

En todo caso quinquenato y precedencia de las elecciones presidenciales junto a las legislativas parece que contribuyeron decisivamente a que el Presidente Sarkozy declarara su propósito de ejercer el cargo, — aun sin mencionarlo expresamente- como un neopremier a la vista de la mutación que ha supuesto que la mayoría parlamentaria deba su misma existencia a la elección presidencial que le precede. Consciente del desequilibrio institucional que ello acarrearía, y ante la transición que parecía haberse iniciado en el 2000 hacia el «presidencialismo absoluto», el Presidente, elegido en 2007, habría creído por consiguiente oportuno introducir cambios constitucionales orientados a «compensar» la presidencialización de las instituciones a través de un reequilibrio de la «arquitectura constitucional de conjunto» ${ }^{28}$.

${ }^{24}$ Para sostener su afirmación Carcassonne puntualiza que tras la reforma ninguno de sus beneficiarios puede decirse que haya obtenido de ella más competencias o una posición distinta que sus predecesores: «aucun des deux présidents qui, dèjá, en ont béneficié, n’en a tiré plus de pouvoir que ses prédécesseurs; tous deux ont eu les mêmes que leurs devanciers, ni plus ni moins». Vid. GUY CARCASSONNE, «Inmuable Ve République», en Pouvoirs, n. 126, «La V République», 2008, p. 31.

${ }^{25}$ Vid. MARIE-CLAIRE PONTHOREAU, «Le Président de la République», Pouvoirs, n. 99, La nouvelle Ve République, 2001, pp. 40-41.

${ }^{26}$ Ibid., p. 41.

27 Vid. STEFANO CECCANTI, «Un assestamento (ancor più marcatamente) monista della forma di governo francese: lo statuto dell'opposizione», en MARINA CALAMO SPECCHIA (a cura di), La Costituzione Francese-La Constitution Française, Torino, 2009, p. 129.

${ }^{28}$ Lettre de mission du Président de la République au Premier ministre Édouard Balladur le 18 juillet 2007, Revue française de droit constitutionnelle, numero hors-série: Après le comité Balladur. Réviser la Constitution en 2008?, 2008, p. 252. 
Ahora bien, en el contexto institucional de la V República esa operación de reequilibrio propuesta por el Presidente y por su partido presentaba notables inconvenientes, al menos en el plano teórico, especialmente por la dificultad de racionalizar las funciones presidenciales respecto a las del Gobierno y por la imposición del Presidente Sarkozy de no alterar la actual inviolabilidad e irresponsabilidad de la institución presidencial.

En efecto, una elemental aplicación de las reglas del gobierno parlamentario exigiría que la facultad de disolución presidencial libre de refrendo cuente con un contrapeso, bien articulando algún mecanismo de exigencia de responsabilidad o bien imponiendo el refrendo al acto de disolución de la cámara baja, actualmente discrecional (art. 12 CF) ${ }^{29}$. Debe sin embargo señalarse que no es la facultad de disolver discrecionalmente por sí sola la que rompe el equilibrio sino su uso partidista, expresión del poder de dirección política que ejerce el Presidente. Si se siguen los esquemas de los gobiernos parlamentarios se echa por tanto en falta una parlamentarización de la prerrogativa de disolución. En este sentido no es ocioso recordar que las tentativas por parlamentarizar la Presidencia de la V República cuentan con una dilatada trayectoria ${ }^{30}$ en su mayoría tratando de aplicar esquemas similares a los de los regímenes primoministeriales electivos y toman su base en la idea de que un reequilibrio entre las instituciones solo puede provenir de un jerarquización formal entre Presidente y Primer Ministro o incluso de la desaparición de esta figura pero manteniendo la facultad presidencial de disolución. Frente a estos intentos han existido iniciativas más propensas a «imitar» el modelo de presidencialismo norteamericano, pronunciándose abiertamente a favor de suprimir la disolución discrecional.

Ahora bien, la pretensión de encontrar una fórmula institucional a partir de los principios de un sistema neo-parlamentario que permita convertir al Presidente en el equivalente de un Premier electivo encuentra como obstáculo la existencia del Primer Ministro. En la actualidad la figura del Primer Ministro es la que permite descargar de responsabilidad al Presidente y ha de verse en efecto como la primera dificultad para transitar hacia un gobierno de presidente-pre-

29 El art. 12 CF solo exige en efecto una previa consulta al Primer Ministro y a los presidentes de las cámaras antes de adoptar la decisión de disolver.

30 Cabe citar por ejemplo la proposición de Achille Peretti (AN doc. 640, proposition de loi constitutionnelle du 7 novembre de 1963), introducida en la Asamblea Nacional en 1963, en 1968 y en 1973, que mantenía el poder de disolución discrecional, con prohibición de disolver durante los 12 primeros meses de legislatura, pero imponía la dimisión presidencial automática al ejercer la disolución de la Asamblea. Vid. RENÉ TEXIDOR, «L'évolution du révisionisme», en OLIVIER DUHAMEL et JEAN-LUC PARODI, La Constitution de la Cinquième République, Paris, 1985, p. 483. 
mier electivo. La existencia del Primer Ministro, en período de coincidencia de mayorías, introduce además una inversión de la responsabilidad política, que según la letra de la Constitución debe residenciarse en el Parlamento pero que de facto se sustancia ante el Presidente al incurrir el Primer Ministro en una práctica hasta ahora constante y que recuerda a una dimisión en blanco. Dicha práctica tiene por consecuencia el cese encubierto del Primer Ministro, careciendo el Presidente de facultad constitucional al efecto, suponiendo otro factor de desequilibrio institucional respecto al Parlamento. De este modo, parecen invertirse los sujetos activo y pasivo de la responsabilidad política, al desplazarse al Presidente el papel activo de control político del Gobierno. De modo análogo, la asunción material por el Presidente de una función directiva sobre el Gobierno cuando existe mayoría del mismo partido hace que se invierta la función constitucional de determinar la política y que según el art. 20 CF corresponde en exclusiva al Gobierno, perdiendo sentido de este modo la exigencia de responsabilidad parlamentaria al Ejecutivo al que en tales circunstancias no se puede considerar el autor de su propia política.

El vaciamiento que este esquema de funcionamiento produce en la responsabilidad política en general y en la del Presidente en particular, fue en parte paliado en su día por la vía de ciertas convenciones constitucionales que, en ausencia de mecanismos institucionales, trataban de hacer efectiva una responsabilidad presidencial de tipo plebiscitario con basamento en las distintas convocatorias electorales. Así, en la época de la presidencia de De Gaulle se impuso la tesis de que Presidente y Parlamento son instituciones de la mayoría electoral $^{31}$, dando lugar a una peculiar responsabilidad política presidencial escalonada e instrumentada a través de las distintas convocatorias en las urnas impulsadas por el Presidente, por lo que tanto el recurso al referéndum como las elecciones legislativas «intermedias» o el uso de la disolución anticipada, ya sea en sentido defensivo como ofensivo, vendrían a ser los instrumentos de equilibrio no institucionales de la presidencia. Este entendimiento de responsabilidad ante el electorado no ha tenido empero ninguna continuidad desde que el presidente De Gaulle dimitiera en 1969 como consecuencia del rechazo en el referéndum de 27 de abril de 1969 de una reforma del Senado. La lectura gaullista que se acaba

31 Esa doble legitimidad democrática del Ejecutivo es la que había esgrimido Duverger para caracterizar el semipresidencialismo francés como un dualismo de responsabilidades que tienden a homologarse, de modo que el sufragio electoral más reciente repercute sobre el más alejado en el tiempo, dando vida a una responsabilidad política presidencial directa (en la reelección) e indirecta (en las elecciones legislativas). Vid. MAURICE DUVERGER, Système presidentiel et système semi-présidentiel, 1986, p. 351. 
de exponer, por más que parezca obedecer a planteamientos de la Ciencia política, tiene hoy en día cierta acogida en el plano de la dogmática constitucional de la función de control, por lo que no debe desdeñarse por entero su relevancia ${ }^{32}$.

\section{LA POSIBILIDAD DE UN CONTROL INSTITUCIONAL AL PRESIDENTE.}

La ausencia de controles institucionales respecto a un Presidente con poderes discrecionales, además de invertir el postulado de que no hay poder sin responsabilidad, coloca a su titular por encima de los jefes del Poder Ejecutivo de los sistemas parlamentarios y presidencial ${ }^{33}$, de suerte que se sitúa en la cúspide de una jerarquización de los tres poderes del Estado, cuya relación con el Presidente es de verticalidad, por lo que no es infrecuente encuadrar el sistema de gobierno de la V República dentro de la tradición cesarista o incluso dentro de lo que en el ámbito politológico americano se conoce como «Presidencia imperial» ${ }^{34}$. Es cierto que la irresponsabilidad política acompaña tradicionalmente a los Presidentes, bien porque el refrendo vacía de contenido decisional sus actos, bien porque una separación estricta entre Ejecutivo y Legislativo impide tener que depender de la confianza parlamentaria, como sucede en la forma de gobierno presidencial. En el caso francés tanto la facultad de disolución de la Asamblea Nacional como el nombramiento del Primer Ministro (art. 5 CF) son actos presidenciales exentos de refrendo contrariamente a lo que sucede en la mayoría de regímenes parlamentarios.

32 Por referirnos a España, autores como Teresa Freixes definen las consultas electorales y los sondeos de opinión como auténticos instrumentos de control del Gobierno. Incluye dentro de las consultas electorales no sólo las que no determinan la formación o reemplazo del Gobierno, sino cualesquiera otros procesos electorales, incluidos los referéndums consultivos. Vid. TERESA FREIXES SANJUÁN, «El control del gobierno a través de las elecciones y de los sondeos de opinión», en FRANCESC PAU I VALL (coord.), Parlamento y Control del Gobierno, Pamplona, 1998, p. 445 .

33 Por ello no es infrecuente afirmar que el Presidente francés suma los poderes del premier británico y del Presidente norteamericano. Vid. MAURO VOLPI, «Le istituzioni francesi viste dall'Italia: L'avversione», en FULCO LANCHESTER e VINCENZO LIPPOLIS, La V Reppublica francese nel dibattito..., op. cit. p. 68.

34 En el sentido definido por Schlesinger: «When the constitutional balance [between Congress and President] is upset in favor of presidential power and at the expense of presidential accountability, the presidency can be said to become imperial.» Vid. ARTHUR SCHLESINGER, The Imperial Presidency, New York, 2004, p. ix. 
Podría pensarse entonces que para restaurar los equilibrios y volver a un diseño parlamentario, bastaría con reformar la Constitución sometiendo a refrendo la facultad de disolución (art. 12 CF) así como el nombramiento del Primer Ministro. Esta posibilidad de extender el refrendo a la totalidad de actos presidenciales no aparece empero como solución atendible en la lógica institucional de la V República en la que la legitimidad que proporciona la elección directa junto al liderazgo y dirección del Presidente del propio partido acaban por subordinar al Primer Ministro a la voluntad presidencial ${ }^{35}$ incluso en aquellos actos en que formalmente se exige el refrendo, pues cuando pertenecen al mismo partido ni siquiera una Constitución normativa puede impedir al Presidente gobernar, como advierte Conac, si el propio Primer Ministro lo admite o incluso lo desea ${ }^{36}$. Así pues, la instauración de mecanismos parlamentarios de control-sanción o de rendición de cuentas sobre el Presidente se encuentra con la dificultad de la ausencia de vínculo fiduciario alguno con las cámaras pues la elección popular constituye una fuente de legitimidad independiente y directa como la que ostenta el Parlamento.

De ahí que la tarea de separar la esfera de responsabilidad en los actos del Presidente como Jefe de Estado por una parte y jefe del Ejecutivo por otra, como ha sugerido Ponthoreau, resulte a la postre inútil a nuestro juicio, ya que ello implicaría configurar dos estatutos jurídicos para un mismo cargo, de modo que la irresponsabilidad e inviolabilidad que acompaña la figura del Jefe de Estado quedaría anulada si se establecen mecanismos de exigencia de responsabilidad política ante las cámaras parlamentarias ${ }^{37}$. Debido a esta dificultad se han explorado otras vías. Entre ellas figura la de someter a un control de constitucionalidad el ejercicio de las facultades presidenciales para restaurar una práctica hoy por hoy no conforme al dictado constitucional ${ }^{38}$. Sin embargo, contra esta

35 No obstante, y como observa Ardant, tal subordinación, que exclusivamente se basa en la lealtad política, no puede medirse con la misma intensidad según qué circunstancias y en todo caso una negativa o un desacuerdo del Primer Ministro con las directrices del Presidente perteneciente al mismo partido han provocado la dimisión del primero (Chirac en 1979 o Mauroy en 1984), lo cual entraña un reconocimiento implícito del Presidente como jefe de la mayoría parlamentaria. Vid. PHILIPPE ARDANT, Le Premier Ministre en France, Paris, 1991, p. 47.

36 Vid. FRANÇOIS LUCHAIRE y GÉRARD CONAC (dirs.), La constitution de la république française, Paris, 1979, p. 154.

37 Vid. MARIE-CLAIRE PONTHOREAU, «Pour une réforme de la responsabilité politique du Président de la République française», en OLIVIER BEAUD et JEAN MICHEL BLANQUER, La responsabilité des gouvernants, Paris, 1999, p. 304.

38 En este sentido, vid. MARIE ANNE COHENDET, La Cobabitation, leçons d'une expérience, Paris, 1993, p. 277.

(C) UNED. Revista de Derecho Político 
solución se apunta que sería inevitable la politización de un órgano como el Conseil Constitutionnel, cuya legitimidad no es la más idónea, pues la naturaleza del control político es de oportunidad, amén la dificultad de construir con criterios jurisdiccionales una categoría y doctrina sobre los actos políticos de la Presidencia y la posibilidad de examinar su finalidad, pues no hay otro tipo de límites constitucionales aparte los de naturaleza procedimental ${ }^{39}$. En realidad pues, no se ve cómo pueda establecerse un control institucional sobre el Presidente de la República como jefe del Ejecutivo sin que al mismo tiempo se vea afectada su condición de jefe de Estado. Esta objeción es esgrimida por quienes rechazan el clásico control-sanción como adaptado a la figura del Presidente.

Dentro de los mecanismos que imponen un control-sanción debemos de incluir la moción de censura sometida a referéndum, los procedimientos de recall y la disolución-sanción. El intento de adaptar el procedimiento de una moción de censura a la Presidencia se ha llevado a cabo entre otros por Patrick Auvret, quien se habría inspirado tanto en el art. 49.2 CF, que contempla la moción de censura como en los mecanismos previstos en la Constitución austriaca e islandesa ${ }^{40}$. El procedimiento no varía en sus fases ni en su objeto, sino que se limita a endurecer la proporción de firmantes exigiendo la quinta parte de la Asamblea Nacional (contra un décimo de diputados prevista para la moción al gobierno) y a prever el sometimiento a referéndum popular de la moción aprobada por la mayoría absoluta de los diputados, en cuyo caso la mayoría afirmativa conllevaría la dimisión del Presidente mientras que un rechazo popular a la moción aprobada por la cámara baja conduce a su disolución automática. Se limita asimismo la posibilidad de plantearla a una sola vez por legislatura o, como mucho, una vez al año. Sin embargo, al igual que ocurre con la moción de censura al gobierno, la excepcionalidad que acompaña a este tipo de control sanción restringe las posibilidades de ser ejercido por parte de la oposición, a lo que debe añadirse su carácter no periódico, ya que al ser excepcional no cabe desde luego ejercerlo con carácter periódico y sobre todo continuado. Asimismo, parece aconsejable proceder a delimitar en el texto constitucional qué tipo de actos podrían estar sujetos a censura o más bien los que deben quedar excluidos por pertenecer al ámbito de la jefatura de Estado, empresa nada fácil.

La celebración por otra parte de una consulta popular para decidir sobre la suerte de la censura a un Presidente suspendido en sus funciones una vez votada favorablemente en la cámara la moción correspondiente, no puede desde luego

39 Vid. M-C. PONTHOREAU, «Pour une réforme de la responsabilité...», op. cit., p. 304.

40 Vid. PATRICK AUVRET, «La Responsabilité du chef de l'État sous la Ve République», Revue de Droit Public, no 1,1988, p. 108. 
parangonarse a una reelección y en cambio sin duda que adquiriría una buena dosis de dramatismo en el normal desarrollo de la actividad de las instituciones. Y ello a pesar de que dicho referéndum intente ser presentado como la aplicación de un principio más general y que algún autor ha propuesto recoger en el texto constitucional, cuya formulación sería: «élu du peuple, le Président de la République ne peut être démis que par lui avec la participation de ceux qui le représentent directement» ${ }^{41}$. Es cierto que a favor de esta lectura se puede invocar la destitución popular como un contrarius actus de la elección directa, naturaleza que en cambio no puede predicarse de la hipotética moción de censura parlamentaria contra el Presidente. Sin embargo cabe considerar a su vez que a quien estaría censurando la Asamblea Nacional sería al jefe del Ejecutivo y no al jefe de Estado, de ahí la legitimidad del control institucional del Parlamento. La preeminencia del Parlamento vendría además reforzada por el dictado del art. 3 CF («La souveraineté nationale appartient au peuple qui l'exerce par ses représentants et par la voie du réferéndum»), que negaría la condición de representante del pueblo al Presidente. Sin embargo, a nosotros nos parece que no cabe negar la condición de representante del Presidente tras el cambio en el sistema de elección en 1962, a pesar de la controversia doctrinal que suscita esta cuestión, pues el artículo 3 no puede referirse al ejercicio de la soberanía en todos los supuestos de voto popular y exceptuarlo para uno: el de la elección del Presidente. Lo que sí debe admitirse es que el tipo de representación del Presidente no puede equipararse a la de los órganos representativos del pluralismo. Ahora bien, como puntualizaba Lucifredi, el Presidente como representante goza de preeminencia respecto al Parlamento en cuanto que es el único órgano en cuya elección toma parte la totalidad del cuerpo electoral. A ello cabe oponer no obstante que tampoco la cualidad de electo del pueblo explica por sí sola la preeminencia del Presidente, como atestiguan otras experiencias como la portuguesa, pues dicha preeminencia viene determinada más bien por el ejercicio político partidista que de sus funciones hace el Presidente sobre la base de la legitimidad popular.

Así pues, y siguiendo este razonamiento, otorgar a la cámara baja un derecho de destitución del Presidente sin realizar una consulta popular sería por tanto poco conforme con la lógica de que cada órgano responde ante la fuente de su po$\operatorname{der}^{42}$. No obstante, desde posiciones contrarias se insiste en la legitimidad de un

${ }^{41}$ Vid. P. AUVRET, «La responsabilité du chef de l'État sous la Ve République», op. cit., p. 106.

42 Vid. DE CAZALS, MARIE, «La Ve République face à l'instauration d'une destitution politique inédite du Président de la République. Retour sur la révision du titre IX de la Constitution du 4 octobre 1958», Revue Française de Droit Constitutionnel, 2007/3, n 71, p. 464.

(C) UNED. Revista de Derecho Político 
control institucional (en este caso ejercido por el Parlamento) y la falta de apoyo constitucional para afirmar que el Presidente responde solo ante el pueblo, una lectura que sólo es imputable a la particular interpretación que De Gaulle hizo de esta Constitución.

La revocación del mandato presidencial pura y simple por iniciativa popular votada en referéndum, esto es, la posibilidad de instaurar un recall tampoco se ha visto exenta de críticas. A pesar de su existencia en regímenes semi-presidencialistas, a contar desde el régimen de Weimar, en la actualidad se le objeta a este mecanismo que el Presidente no recibe un mandato imperativo, en base al cual sus electores puedan actuar en cualquier momento por estimar que sus instrucciones no han sido atendidas ${ }^{43}$.

La experiencia comparada se ha tenido igualmente presente en lo que se refiere a la posibilidad de instaurar un impeachment a la americana. A este respecto la preparación de la reforma constitucional de 2007 para modificar el art. 68 CF abrió una reflexión en torno a dicha posibilidad. Es cierto que en su nueva literalidad se debe excluir del nuevo art. 68 CF proceder a la destitución del Presidente por ilícitos penales, como parecía desprenderse de la redacción anterior de este precepto, si bien voces autorizadas discrepaban de esa interpretación. Desde 2007 sin embargo las cámaras no ejercen ni se constituyen como Corte de Justicia sino sólo como Alta Corte y tanto la nueva composición de la Corte, que son ambas cámaras por entero (anteriormente 24 parlamentarios eran investidos de poderes judiciales), como el procedimiento y el nuevo tenor que vincula el examen de la conducta del Presidente a una falta de sus deberes manifiestamente incompatible con el ejercicio de su mandato, llevan a la conclusión de que no se trata de un procedimiento ni penal ni jurisdiccional. El procedimiento, en efecto, en todas sus fases está inspirado en el que regula la moción de censura en el art. 42 CF. Sin embargo el tipo de responsabilidad exigido no es el mismo que el existente en un régimen parlamentario entre gobierno y Parlamento. Además la excepcionalidad y extrema ratio de este procedimiento llevan a descartar cualquier paralelismo. Por esta misma razón la crítica basada en la exclusión en este procedimiento de una ratificación popular resulta infundada ya que la responsabilidad exigida al Presidente no deriva del normal ejercicio de sus funciones ni de su balance de gestión, sino de hechos de una tal gravedad que bien podría decirse que constituyen una causa de indignidad.

43 Cfr. MARCEL SIKONDO, «La Constitution de la $\mathrm{V}^{\mathrm{e}}$ ou le pouvoir assagi par la démocratie», Revue Politique et Parlementaire», 1998, n. 997, p. 64. 
Así pues, no ha habido en la doctrina una respuesta satisfactoria a la instauración de mecanismos de exigencia de responsabilidad del Presidente en tanto que jefe del poder ejecutivo. Si se hace depender la responsabilidad de la valoración del electorado sobre el balance de gestión en las elecciones presidenciales, queda entonces excluida por entero la responsabilidad entendida como rendición de cuentas ordinaria. Para algunos autores y según esta lógica gaulliana la responsabilidad presidencial se reduciría por tanto al mecanismo indirecto de las elecciones, al uso del referéndum y al difuso control del «tribunal de la opinión pública». De ahí que el ajuste que supuso la reforma constitucional del quinquenato fuera valorada como un paso más en la contextualización de la «responsabilidad electoral» del Presidente que se presenta a la reelección. Sin embargo la cuestión que sigue estando abierta es la de si a un Presidente con poderes de jefe del ejecutivo puede ser objeto de un control institucional del Parlamento, entendiendo por tal no ya el control-sanción sino el control del balance de gestión. Así, por ejemplo, en el semipresidencialismo republicano de Weimar tampoco la acción del Presidente era objeto del control ordinario del Parlamento. Allí un referéndum popular de recall confirma la teoría de que la irresponsabilidad parlamentaria del Presidente tiene que ver con la legitimidad popular de la elección presidencial.

Otra serie de argumentos para negar un control institucional ordinario del Presidente parten de un análisis estrictamente formal de su función constitucional y de sus poderes. Si se consideran cuáles son los poderes exentos de refrendo, constantemente traídos a colación para explicar el contenido político de los mismos especialmente en el caso de la disolución, se observa en efecto que no suponen una continuidad de la acción de gobierno sino que son, como acertadamente observa Sartori, poderes discontinuos y de carácter excepcional, de imposible ejercicio ordinario ${ }^{44}$. No debe olvidarse que la tríada nombramiento-cese-disolución aparecía sin embargo como atributo esencial del Monarca constitucional en los llamados regímenes de doble responsabilidad. Pero es sustancialmente cierto que la Constitución no encomienda al Presidente una función de dirección política o siquiera de impulso o de dirección del Gobierno. La función de árbitro y garante del art. $5 \mathrm{CF}$, por más que se intente interpretar de manera elástica no se refiere a un poder de dirección política o de determinación de las directrices gubernamentales. De hecho, un rigor formalista excesivo en la interpretación del conjunto de atribuciones presidenciales, en combinación con esa función de ga-

44 Vid. GIOVANNI SARTORI, Ingegneria costituzionale comparata, Bologna, $3^{\text {a }}$ ed., 1998, p. 136.

(C) UNED. Revista de Derecho Político 
rante y árbitro, conduce casi de manera inevitable a afirmar la violación sistemática de la Constitución o incluso constatar una mutación.

Antes ya se ha hecho referencia a la dificultad en construir una responsabilidad de los actos presidenciales a través del mecanismo del refrendo porque la aquiescencia de un Primer Ministro priva a esta técnica de cualquier virtualidad. Acabamos de examinar ahora también las dificultades que plantea la implantación de un control político a la gestión del Presidente. Todo ello hace que la única vía para construir algo parecido a un control político sobre los actos presidenciales sea la compartición competencial o la tímida apertura a un control jurisdiccional de constitucionalidad. Se encuentran ejemplos de ello en algunas de las reformas introducidas por la revisión de 2008, en concreto la relativa al poder de nombramiento de los altos cargos y en la que afecta a la declaración del estado de crisis. En cuanto al primero, el nuevo art. 13 CF dispone que los nombramientos presidenciales vayan precedidos del parecer conforme de las dos comisiones permanentes de nombramientos del Parlamento, si bien para expresar la disconformidad con un nombramiento se exige el pronunciamiento desfavorable de una mayoría de 3/5 y aun así carece de efecto vinculante. En el art. 16 reformado se prevé que superados los treinta días de la declaración del estado de crisis, los presidentes de las cámaras, o 60 diputados, o igual número de senadores, puedan instar al Conseil Constitutionnel para que verifique la permanencia de los presupuestos constitucionales que permiten el ejercicio de esta facultad.

Sin embargo es evidente que este tipo de actos como los que se acaban de citar no entran dentro de la categoría de actos de dirección política y ello porque en primer lugar éstos por su propia naturaleza deben ser ajenos a cualquier control jurídico y en segundo lugar, porque el parecer en los actos de nombramiento a lo más se les puede tener por actos de autorización, pero no actos de control strictu sensu. De ello se sigue que las limitaciones impuestas por un control jurídico o por el concurso parlamentario dejan al descubierto las facultades de dirección política que ejerce el Presidente y que desde la presidencia Giscard de manera indisimulada se instrumentan a través de cartas de misión, además de la presidencia material y no sólo formal del Consejo de Ministros. La función de dirección e impulso político no halla por lo demás su soporte en actos como puede fácilmente deducirse de la propia naturaleza de dicha función, cuyo control no versa sobre actos concretos sino sobre un conjunto de acciones directivas desde un punto de vista de oportunidad política. Queda así puesto de relieve que la determinación de la política solo es fiscalizable o en todo caso residenciable en órganos de control político. Este extremo resulta clave para entender por qué las otras dos vías intentadas en la fase de consulta de la reforma de 2008, y que han corrido dispar fortuna, han incidido en las relaciones del Presidente con el Par- 
lamento a través de los discursos a las cámaras y de la información en comisiones de investigación o de estudio. En ambos casos se ha excluido de la propuesta presidencial de reforma la posibilidad de votar resoluciones o mociones, aspecto que ha merecido críticas por excluir el ejercicio de la función de control parlamentario.

Pero antes de pasar a examinar brevemente los dos mecanismos con los que se ha pretendido configurar una suerte de accountability a la francesa del Presidente, debe observarse que, pese a los juicios críticos que ha recibido, no parece del todo desacertada la exclusión de un voto tras el debate posterior al discurso del Presidente ante las cámaras, ni parece merecedora de crítica la imposibilidad de que el Presidente se someta a las preguntas de una comisión parlamentaria si tomara la iniciativa de comparecer, ya que debe tenerse en cuenta que la fuente de legitimidad democrática directa del Presidente limita el monopolio parlamentario de la expresión de la voluntad popular, por lo que las directrices políticas presidenciales no debieran ser objeto de control político, siendo legítimo que toda comparecencia del Presidente se limite a informaciones a las cámaras, siguiendo una interpretación del todo análoga a la que se viene sosteniendo para el presidencialismo norteamericano según la cual el legislativo no puede revisar la adecuación de la actuación presidencial a una voluntad popular cuya representación competiera solo y exclusivamente a los órganos parlamentarios ${ }^{45}$.

\section{A) El derecho de dirigir mensajes y alocuciones a las Cámaras}

Hasta ahora el denominado derecho de mensaje había venido siendo entendido como garantía y como límite de la separación de poderes. Garantía en el sentido de preservar la irresponsabilidad política del Presidente y límite también para el Parlamento, que no puede debatir sobre los mensajes presidenciales, garantizando así también la autonomía de la Jefatura del Estado quien directamente comunica a la Nación y no a sus representantes (art. 16 CF). La modificación del art. $18 \mathrm{CF}$, donde se recoge este derecho, paradójicamente no ha alterado del todo ese sentido garantista y limitador para el Parlamento. Más bien la reforma ha consistido en permitir el acceso del Presidente a las cámaras manteniendo la posibilidad del tradicional mensaje leído sin su presencia, lo cual incorpora un nuevo derecho o facultad presidencial consistente en hacer uso de la

45 Vid. LUIS LÓPEZ GUERRA, «La función de control de los Parlamentos: problemas actuales», en ÁNGEL GARRORENA MORALES (ed.), El Parlamento y sus transformaciones actuales, Madrid, 1990, p. 238.

(C) UNED. Revista de Derecho Político 
palabra en presencia de las cámaras convocadas al efecto. Esta nueva facultad responde al espíritu de la reforma de reequilibrar las instituciones, en este caso potenciando al Parlamento. De hecho, las posibilidades que abre la desaparición de la prohibición constitucional de intervención del Presidente ante las cámaras se ha querido presentar como un importante avance en el reequilibrio institucional por el protagonismo devuelto al Parlamento, hasta el punto de que la lectura de discursos del Presidente a las cámaras con la posibilidad de un posterior debate parlamentario ha venido a ser uno de los pilares de la reforma de 2008. Se ha criticado sin embargo que permitir la intervención del Presidente ante las cámaras tenga un sentido reequilibrador, puesto que tal modificación ha de ser puesta en relación con otro contenido de la reforma como es la limitación en la reelección, que viene a transformar el discurso presidencial en el discurso del jefe de la mayoría y del Ejecutivo perdiendo el carácter de discurso de Jefe de Estado rassembleur ${ }^{46}$.

La posibilidad de dirigir un discurso a las cámaras se ha configurado como un derecho del Presidente, a quien basta formular la petición para poder llevarlo a cabo. Sobre el contenido del mensaje no pesa además límite alguno. Aunque se barajó la posibilidad en el Comité «Balladur» de ofrecer la posibilidad de dirigirse tanto a una sola cámara como a ambas, se ha optado por el legislador de la reforma por contemplar tan sólo el mensaje a las cámaras reunidas en sesión conjunta, esto es, en Congrès. Significativamente la presencia del Presidente en las cámaras se configura como una potestad libre de refrendo, de consulta o de propuesta ya que no figura entre los actos sometidos a refrendo del art. 19 CF.

Parece entonces conveniente responder a la cuestión de si con esta presencia en las cámaras, - instrumentada en la iniciativa de hacer uso de la palabra con un discurso_- , se ha pretendido prefigurar una suerte de rendición de cuentas del Presidente ante las cámaras, buscando así incorporar mecanismos típicos del sistema parlamentario o en última instancia una cierta responsiveness. No ha de olvidarse a este respecto que en este mismo art. 18 CF el Comité de reflexión de la reforma contemplaba como propuesta una reforma del texto constitucional que permitiera también la comparecencia a solicitud del Presidente en comisiones parlamentarias de estudio o de investigación. La respuesta que se ha de dar a si se

46 La exclusión de un voto tras el debate sobre el discurso del Presidente hace que esta nueva facultad de poder hacer uso de la palabra ante las cámaras no pueda ser calificada de reequilibradora ya que no puede tener ya el carácter de discurso de una institución neutral. Vid. STEFANO CECCANTI, «Lo Statuto dell'Opposizione in Francia per una nuova valorizzazione del Parlamento», en F. LANCHESTER e V. LIPPOLIS, La V Repubblicafrancese nel dibattito..., op. cit., p. 270 . 
ha configurado un mecanismo de dación de cuentas para el Presidente parece empero que debe ser negativa en ambos casos. La facultad del Presidente de dirigirse a las cámaras no puede considerarse un debate con éstas toda vez que aunque se ha dejado abierta la posibilidad de debatir sobre su contenido, la imposición de hacerlo en ausencia del Presidente elimina toda posibilidad de considerarlo un auténtico debate. Resulta además que los discursos presidenciales representan el único medio de comunicación en los sistemas de estricta separación de poderes, o sea en los regímenes presidenciales. Por tanto, no se puede afirmar que estemos ante una dación de cuentas, antes bien, no parece que en cuanto al contenido el discurso presidencial vaya a apartarse del anuncio de iniciativas, o la mera formulación de recomendaciones, objetivos o necesidades más que estar dirigido a explicar la gestión presidencial.

La exclusión de toda votación sobre el discurso presidencial tiende además, como se ya ha dicho, a preservar la esfera de irresponsabilidad política, observable además en el hecho de que sólo se haya previsto al final la posibilidad de dirigirse a ambas cámaras conjuntamente y no por separado, intentando así evitar quizás la tentación de aplicar el reglamento de cada cámara y en particular el de la Asamblea Nacional.

Conviene además precisar que es difícil de determinar la naturaleza del debate posterior al discurso pronunciado por el Presidente, ya que aunque pudiera aproximarse al de un debate general, tampoco se encuadra formalmente en los debates de comunicaciones del Gobierno existente en los reglamentos de las cámaras, aunque es cierto que tiene casi idéntico tratamiento.

En todo caso, la facultad de dirigir un discurso a las cámaras no va más allá de lo que se puede considerar una responsabilidad política difusa desprovista de todo contenido jurídico, y en consecuencia medible solo en términos de responsiveness ${ }^{47}$. Se ha dicho a este respecto que la prohibición de un voto tras el eventual debate de los grupos parlamentarios sobre el discurso del Presidente trataría precisamente de preservar la separación de poderes. Sin embargo cabe dudar que el principio de separación de poderes se aplique aquí como un principio formal,

47 El concepto de responsiveness a través de los discursos se encuentra bastante consolidado en la ciencia política norteamericana y alude a todo acto de comunicación para abordar los problemas del país ante la opinión pública, si bien, en el caso de los mensajes presidenciales sobre el estado de la Unión, dirigiéndose a las cámaras parlamentarias. Sobre el uso de este concepto los discursos presidenciales sobre el estado de la Unión vid., CANES-WRONE, BRANDICE and KENNETH W. SHOTTS, «The Conditional Nature of Presidential Responsiveness to Public Opinion.» American Journal of Political Science n.48, 2004, October, pp. 690-706; JEFREY E. COHEN, Presidential Responsiveness and Public Policy-Making, Michigan, 2002.

(C) UNED. Revista de Derecho Político

N. ${ }^{\circ} 81$, mayo-agosto 2011, págs. 199-242 
ya que en la Constitución de 1958 presenta un contenido más bien material, como es el de preservar la estabilidad gubernamental, por lo que la privación a las cámaras de votar resoluciones sobre los discursos del Presidente de la República tiene más bien la naturaleza de una limitación de carácter racionalizador del poder parlamentario, muy similar a la que ha venido impidiendo a las cámaras votar cualquier tipo de resolución dirigida al Gobierno según la interpretación dada por el Conseil Constitutionnel en las decisiones Règlement AN (Decisiones 59-2, de 17,18 y 24 de junio de 1959) y Règlement du Sénat (Decisiones 59-3 de 24 y 25 de junio de 1959$)^{48}$, jurisprudencia ahora evitada con la constitucionalización expresa del voto de mociones parlamentarias como un mecanismo más de control ordinario tal y como venía proponiendo la doctrina ${ }^{49}$.

El art. 18 CF menciona también expresamente que la reunión de las cámaras puede celebrarse incluso fuera del período de sesiones. Ello plantea la duda de si la convocatoria presidencial fuera del período de sesiones ordinario puede considerarse como sesión extraordinaria de las cámaras pues en tal caso el decreto de convocatoria debe de ir refrendado ${ }^{50}$. Con la redacción anterior la doctrina ya venía considerando que la convocatoria de las cámaras por el Presidente no tendría el carácter de sesión parlamentaria, lo cual eximiría de refrendo el decreto presidencial de convocatoria lo que parece más conforme a la naturaleza de facultad autónoma del Presidente distinta de una convocatoria del Gobierno. En cualquier caso, nunca hasta hoy se ha convocado a las cámaras fuera del período de sesiones por lo que no existe práctica al respecto.

\section{B) La comparecencia del Presidente en comisiones de investigación}

Más discutible ha sido la propuesta de incluir en el texto constitucional la facultad de comparecer a petición del Presidente en comisiones de encuesta e investigación. Todo apunta a que aparece aquí de nuevo el interés por colocar al Presidente en una posición similar a la del Gobierno en los debates parlamentarios. Hay

$48 \mathrm{Al}$ respecto, vid. MARTHE FATIN-ROUGE STÉFANINI, «Le Conseil constitutionnel dans la révision constitutionnelle du 23 juillet 2008 sur la modernisation des institutions», Revue française de droit constitutionnel, $\mathrm{n}^{\circ}$ 78, Avril 2009, p. 273.

49 Vid. BRUNO BEAUFUMÉ, «La réhabilitation des résolutions : une nécessité constitutionnelle», Revue de droit public, 1994, p. 1399.

50 Para ilustrar los términos del debate en la doctrina, vid. GINEVRA CERRINA FERONI, «Il potere di messaggio del Presidente della Repubblica nell'esperienza della V Repubblica francese», en MARINA CALAMO SPECCHIA (a cura di), La Costituzione francese-La Constitution française, op. cit., p. 333. 
que destacar que, al contrario del resto de propuestas analizadas, todas ellas con una cierta tradición en Informes e iniciativas de reforma, la comparecencia del Presidente en comisiones de encuesta resulta del todo novedosa en el panorama del reformismo constitucional en la V República. Cabe preguntarse si la declaración del Presidente en una comisión parlamentaria pretende un acercamiento a la lógica de un sistema parlamentario o a una suerte de dación de cuentas o incluso si constituye un mecanismo de exigencia de información, habida cuenta del carácter de este tipo de comisiones parlamentarias. Para encontrar una respuesta debe de tenerse en cuenta en primer lugar que en la propuesta del Comité las cámaras no pueden llamar a declarar al Presidente, lo que parece resultaría contrario al tenor del art. 67 CF, que prohíbe citar a declarar al Presidente de la República ante toda autoridad judicial o administrativa, incluyendo la declaración sólo para proporcionar información. Por tanto, lo que se recoge en la propuesta del Comité es la facultad de declarar (sobre hechos) o de informar (sobre propuestas) cuando lo estime conveniente el Presidente y a petición propia, sin que la comisión pueda rechazar además dicha intervención. Conviene por tanto tener presente que la iniciativa del Presidente de intervenir en la comisión se hace sin contar con la voluntad del órgano parlamentario al que se le impone la obligación de escuchar al Presidente. Se ha criticado por este motivo esta propuesta al no respetar la división de poderes, en cuanto que el Presidente no debe su elección a ninguna de las cámaras, con las que no le liga tampoco ninguna relación de confianza. Sin embargo alguna utilidad puede tener una comparecencia del Presidente en este tipo de comisiones si analizamos un precedente, el de la llamada comisión sobre las enfermeras búlgaras en Libia y que además tuvo lugar poco antes del envío de la carta de misión del Presidente al Comité Balladur. En efecto, en el año 2007 se crea una comisión destinada a investigar los hechos y circunstancias en los que la esposa del Presidente de la República, Cécilia Sarkozy, acompañada del Secretario General del Elíseo, se desplazaron a Libia para negociar la liberación de unas enfermeras búlgaras condenadas a pena de muerte. Ante una eventual petición de comparecencia de la esposa del Presidente en la comisión parlamentaria que investigaba los hechos, el portavoz del Elíseo calificaba esta posibilidad de inconstitucional ya que el propio Presidente, si bien con posterioridad a los hechos, informó que su esposa había actuado como su enviada personal, de modo que se beneficiaría del estatuto de la inmunidad presidencial. La propuesta de que el Presidente sea oído en una comisión de investigación habría sido de este modo un medio de corregir lo que ocurrió en el episodio de las enfermeras ${ }^{51}$. Debe de recordarse aquí que la in-

51 Vid. MICHEL VERPEAUX, «Moderniser et équilibrer les institutions de la Ve République. Premières réflexions sur 77 propositions», La Semaine Juridique Édition Générale, n. 46, 2007 , p. 20.

(C) UNED. Revista de Derecho Político 
munidad que reconoce el art. $67 \mathrm{CF}$ al Presidente fue objeto de una considerable extensión en 2003, yendo mucho más allá de la tradicional inmunidad penal que caracteriza a la mayoría de jefes de Estado, al impedir indagaciones de órganos jurisdiccionales o administrativos sobre hechos o actos en los que pudiera haber tomado parte el Presidente, creando una suerte de inmunidad no sólo jurisdiccional sino también administrativa, y que habría tenido su excepción en esta propuesta del Comité para introducir la comparecencia a petición propia del Presidente ante comisiones de investigación parlamentaria.

Como ya se ha indicado, se ha tratado de justificar la improcedencia de introducir en el art.18 CF la facultad de efectuar una comparecencia a petición propia del Presidente ante una comisión de estudio o de investigación acudiendo al principio de separación de poderes. Dicha separación es característica de los sistemas presidenciales respecto del cabeza del Ejecutivo, mientras que esa separación se invierte en los regímenes parlamentarios, y ello porque existe la facultad de informar o de comparecer a petición propia del Primer Ministro, a título de jefe de un Ejecutivo responsable, mientras que la separación respecto del Parlamento y sus comisiones rige en cambio de manera estricta para el Jefe de Estado, excluido por completo de la dirección del Ejecutivo.

Sin embargo, cabe dudar de que una comparecencia voluntaria quede cubierta por el ámbito de la inmunidad e irresponsabilidad del Jefe del Estado, ya que ésta operaría como garantía de irresponsabilidad solo para cuando el Presidente sea citado a una comisión y no en el caso contrario, dado que el fundamento de la inmunidad es la no perturbación del ejercicio del cargo por parte de otros poderes. No parece que pueda ser éste el fundamento de la exclusión de una declaración a petición propia ante una comisión: más que preservar de perturbaciones el ejercicio de la Presidencia cuya irresponsabilidad no puede verse alterada, cabría hablar más bien de preservar al Parlamento de "perturbaciones» provenientes del Presidente.

\section{EL PROBLEMA DE LA DELIMITACIÓN DE FUNCIONES ENTRE PRESIDENTE Y PRIMER MINISTRO: LA FUNCIÓN DE GOBIERNO}

La dirección política del Presidente se ha convertido en Francia en una práctica material distanciada de la lógica arbitral que parece imponerle la Constitución y que ejerce especialmente en el ámbito de las relaciones con el Primer Ministro, y sobre todo en el funcionamiento real del Consejo de Ministros. Respecto a lo primero, con mayoría presidencial y parlamentarias coincidentes, sólo la aceptación por parte del Primer Ministro del liderazgo político y de partido del Presidente puede explicar 
que aquél acate sus directrices, siendo por tanto un hecho y no una norma, porque como ha destacado Fabbrini el liderazgo presidencial excede el entendimiento formal del enunciado de preceptos jurídico-constitucionales ${ }^{52}$. La confianza gubernamental en estos casos, en los que se presupone que no hay disonancias entre mayoría presidencial y parlamentaria, procederá del Presidente y no del Parlamento, pues aquél es el jefe de la mayoría de éste; por eso es correcto afirmar que en puridad no existe un gobierno de doble confianza, al menos si nos referimos a la confianza inicial homóloga a una investidura tácita ${ }^{53}$. En cuanto a lo segundo, es cierto que la presidencia del Consejo de ministros por parte del Jefe del Estado es una prerrogativa tradicional en el derecho constitucional francés, sin embargo el Presidente se beneficia de la escasa o nula racionalización y formalización de frenos y contrapesos en las deliberaciones del Consejo de Ministros. Esta carencia viene siendo apuntada además como una distorsión y un riesgo de incurrir en el ejercicio de un gobierno personalista ${ }^{54}$. Exceptuando pues los casos de cohabitación, previsiblemente más improbables después de 2002, el Presidente ejerce competencias que formalmente corresponden al Primer Ministro, dando pie no tanto a una invasión competencial cuanto a una superposición de ámbitos o domaines de perfiles muy imprecisos. Tratando de distinguirlos, se introdujo tempranamente la llamada teoría del domaine reservé, acuñada en tiempos de De Gaulle, para justificar poderes propios del Presidente en el ámbito de las relaciones internacionales y de la Defensa. Pero, como observa Marie-Anne Cohendet, la práctica presidencial ha sido la de incidir en todos los campos de la política en flagrante contradicción con la Constitución y con la ordenanza de 7 de enero de 1959 sobre los poderes del Gobierno de tal modo que no ha existido tal domaine reserve $e^{55}$. La teoría del domaine reservé ha tenido acogida con

52 Afirma este autor que «[... la la leadership è qualcosa di più di un effetto prodotto da un sistema di norme, proprio come la politica è un'attività che inevitabilmente trascende l'organizzazione giuridica dello stato (anche se da quest'ultima non può prescindere». SERGIO FABBRINI, Il Principe democratico. La leadership nelle democrazie contemporanee, Roma-Bari, 1999, p. 61.

53 La apreciación que hacía en su momento Leopoldo Elia nos parece por ello acertada: «tertium non datur...o il Governo procederà dal Presidente, sia pure con la 'fiducia di rincalzo' dell'Assemblea...o il Governo procederà dal Parlamento». Vid. LEPOLDO ELIA, «Governo (forme di)», en Enciclopedia del Diritto, vol. XIX, 1970, p. 645.

54 García Roca considera por ello que la formalización de un procedimiento que no tiene por qué ser el común administrativo es una salvaguardia de la estructura compleja tanto del Gobierno como del Consejo de Ministros y supondría además una regla interna de división de poderes. Vid. JAVIER GARCÍA ROCA, «La fragilidad de los Ministros (de su competencia y responsabilidad directas)», Cuadernos de Derecho Público, n. 18, enero-abril, 2003, p. 66.

55 Vid. MARIE-ANNE COHENDET, «Article 21», en FRANÇOIS LUCHAIRE, GÉRARD CONAC, XAVIER PRÉTOT (dirs.), La Constitution de la République française. Analyses et commentaires, $3^{\mathrm{a}}$ ed., Paris, 2009, p. 621. 
posterioridad en los períodos de cohabitación, lo que representa una contradicción aún mayor, pues se entiende que en tales circunstancias el Presidente se repliega a la figura de un Jefe de Estado parlamentario. De ahí que la preocupación por adecuar el texto constitucional a la práctica en dicho ámbito fuera uno de los puntos más destacados en la carta del encargo presidencial hecho al Comité Balladur, en la que se solicita un estudio de los artículos a modificar a fin de obtener un reconocimiento formal la dirección presidencial del Ejecutivo que se viene practicando de manera ininterrumpida salvo en los casos de cohabitación. Así pues, uno de los fines perseguidos con la reforma de 2008 ha sido el de tratar de adecuar la letra de la Constitución a la práctica institucional.

La delimitación de funciones solicitada al Comité debía realizarse además respetando la condición impuesta por la carta de misión en la que el Presidente encomendaba el estudio sobre la reforma y en la que imponía de manera expresa que la nueva articulación de competencias entre Presidente y Primer Ministro debía de mantener el régimen de responsabilidad aplicable hasta ahora a cada uno de ellos ${ }^{56}$. Las propuestas del Comité para delimitar más claramente el domaine presidencial y gubernamental se centran en los arts. 5, 20 y 21 CF. Sin embargo en su informe el Comité no procedió a una delimitación material sino funcional, introduciendo entre las funciones del Presidente de la República enunciadas en el art. 5 CF la de «definir la política de la Nación» lo que de manera correlativa y por congruencia conllevaba suprimir la función, que hasta ahora venía correspondiendo al Gobierno (art. 20 CF), de determinar la política de la Nación.

Respecto a la función que el Comité propone incluir en el art. 5 CF, y que hace recaer expresamente en el Presidente la decisión sobre la política a seguir, el Informe sobre Modificaciones estima que en época de gobierno del partido presidencial la formalización de esta función se hace innecesaria, si bien tendría como ventaja ajustar la letra de la Constitución a la práctica en tales circunstancias de coincidencia de mayorías ${ }^{57}$. En cambio esa constitucionalización de la función de dirección política atribuida al Presidente introduciría un elemento de ri-

56 «Il concient dès lors: [...] d'examiner dans quelle mesure les articles de la Constitution qui précisent l'articulation des pouvoirs du président de la République et du Premier ministre devraient être clarifiés pour prendre acte de l'évolution qui a fait du président de la République le chef de l'exécutif, étant observé toutefois que cette articulation n'est guère dissociable du régime de responsabilité actuellement en vigueur...». Vid. «Lettre de mission du président de la République», Paris, le 18 juillet 2007, en COMITÉ DE RÉFLEXION ET DE PROPOSITION SUR LA MODERNISATION ET LE RÉÉQUILIBRAGE DES INSTITUTIONS DE LA V ${ }^{e}$ RÉPUBLIQUE, Une Ve République plus démocratique, Paris, Fayard, 2008, p. 208.

57 Vid. Une Ve République plus démocratique, Paris, Fayard, 2008, p. 30. 
gidez que en caso de cohabitación iría contra las reglas del sistema parlamentario y también contra el principio de unidad de dicha función de dirección política, pues la diarquía existente fracturaría dicha función en dos. Consecuencia lógica y necesaria de atribuir la determinación de la política al Presidente sería por otra parte conferirle la facultad de cese del Primer Ministro, lo que sin duda contribuiría a la unificación del poder Ejecutivo en la figura del Presidente. Sin embargo dicha facultad carecería de normatividad ante una posible cohabitación, pues en tal caso de manera automática, y por el juego del sistema parlamentario, el Primer Ministro sería jefe de la mayoría parlamentaria en la Asamblea y jefe del Gobierno. En buena sustancia pues, los mecanismos de la forma de gobierno parlamentaria operan ya como una suerte de régimen de autorregulación del monismo mayoritario.

En este sentido, el Comité reconoce que aunque también en el presidencialismo norteamericano existe la divergencia entre Ejecutivo y Legislativo, no tiene por consecuencia el cuestionamiento de la unidad del Ejecutivo que en Francia es puesta en entredicho por la cohabitación. Descartado el presidencialismo quedaba al Comité como única opción estudiar la introducción de algún mecanismo que excluya las cohabitaciones. Un primer remedio es hacer coincidir las elecciones presidenciales y legislativas tomando como ejemplo un modelo que ya ha existido en Rumanía, lo cual supone introducir un elemento de los sistemas de neopremier (pero también del presidencialismo) consistente en este caso en hacer coincidir la segunda vuelta de las elecciones presidenciales con la primera vuelta de las legislativas ${ }^{58}$. Pero incluso dando por bueno que dicha coincidencia produciría el ansiado acompasamiento de mayorías, sería ineludible decretar la disolución automática de la Asamblea cada vez que por determinadas circunstancias sobrevenidas se debiera proceder a un adelanto de las elecciones a la Presidencia de la República en casos tales como la vacante producida por fallecimiento, dimisión o enfermedad incapacitadora ${ }^{59}$. El Comité examina tales mecanismos pero los desestima por arriesgados y rigidificadores. A la inversa, sin producirse ninguna vacante, las mayorías se pueden volver a desequilibrar si la decisión de disolver separara en el calendario las elecciones legislativas de las presidenciales, situación en la que el Informe del Comité valoraba la posibilidad de

58 Vid. Une République..., op. cit., p. 32.

59 La razón de haber desestimado una disolución automática en caso de fallecimiento o dimisión del Presidente y de imponer su dimisión en caso de decretar la disolución de la Asamblea estriba en la posible desestabilización y vacío de poder que se podría crear por lo que dicha solución aparece como demasiado gravosa. Vid. «Rapport de la Commission Balladur: Libres propos croisés de Pierre Mazeaud et Olivier Schrameck», Revue du Droit Public, t. 124, n 1, 2008, p. 12.

(C) UNED. Revista de Derecho Político 
imponer en el texto constitucional la dimisión al Presidente que sufriera un revés en las primeras, aunque a la postre desestimaba tal solución al considerar que tiene un difícil encaje en la Constitución ${ }^{60}$.

Aun con todas estas dificultades apuntadas por el propio Comité, su decisión (de la mayoría) es proponer añadir al art. 5 CF que enumera las funciones del Presidente, la siguiente: «Él [Presidente] define la política de la nación» y de manera paralela suprimir la función análoga que el art. 20 CF atribuye al Gobierno: «El gobierno determina [... ] la política de la nación». Con ello se pretende establecer una separación acorde a lo que viene siendo la práctica en los períodos de coincidencia de mayorías, comportando una ampliación de las funciones actuales, más propias de un «Presidente-garante», para acercarlas a las de un «Presidente-gobernante». La definición por el Presidente de la política fue una opción ya barajada en el momento constituyente. Didier Maus ha recordado cómo en junio de 1958 se descartó un artículo al que califica de «maravilloso» por el grado de adecuación que presenta con la evolución institucional que ha seguido la V República. Se refiere a este texto: «Assisté du gouvernement, le président de la République détermine les grandes orientations de la politique nationale et veille à leur mise en ouvre» ${ }^{61}$. Pues bien, sabido es que la preocupación fundamental en el diseño original del texto constitucional fue la de conceder al Presidente los poderes para dirigir un Parlamento de mayorías cambiantes, poco estables y con falta de una fuerte cohesión. Es decir, se trabajó en todo momento con la hipótesis de la ausencia de mayorías amplias, bien cohesionadas y estables. La ausencia para los redactores del texto de 1958 de lo que hoy la doctrina denomina hecho mayoritario impidió ver en su día que el Primer ministro podía, con un partido fuerte y cohesionado, prescindir de la «tutela» presidencial que asegurara la estabilidad gubernamental. Sin embargo, en la actualidad toda reforma constitucional parece que no debiera prescindir de que cualquier nueva función que se atribuya al Presidente no debe contradecir el parlamentarismo mayoritario y por tanto salvo con mayoría del mismo partido es evidente que nulo o escaso margen tendrá el Presidente en la facultad de encargar gobierno a un Primer ministro que no necesita tutela alguna. Cabe pues interrogarse si tendría algún sentido la redacción que, aunque a la postre no incluida en el proyecto de reforma de 2008, contemplaba trasladar la función de dirección política del Gobierno al Presidente. Recordemos que esta es una función típica del Premier,

60 Vid. Une République..., op. cit., p. 30.

${ }^{61}$ Cfr. G. BERGOLEY, D. MAUS, J.C. COLLIARD, J.L. PARODI, R. JANOT, J.F. PREVOST, G. LE GALL, B. CLUZEL y M. GUASTONI, «Constitution: 40 ans après, la nécessaire révision?», Revue politique et parlementaire, n. 997, novembre-décembre 1998, p. 15. 
por lo que procede ahora indagar sobre si han sido solo motivos de oportunidad los que han aconsejado no incluirlo en la iniciativa de revisión constitucional o si también han podido existir motivos de carácter más bien teórico los que han desaconsejado tal inclusión.

Nos parece interesante la propuesta que realizó el Comité en su informe y ello a pesar de no haber sido incluida tan siquiera en el proyecto de ley de revisión, ya que sirve para determinar si el semipresidencialismo francés puede evolucionar estructuralmente hacia un gobierno de neopremier o si por el contrario lo impiden ciertos límites. ¿Por qué atribuir al Presidente de la República la definición de la política otorgándole un título constitucional que en caso de cohabitación puede resultar opuesto a las reglas del juego parlamentario, que harán recaer sin norma escrita dicha función en el Primer Ministro? Evidentemente la modificación que se proponía al art. 5 CF no dice que la definición de la política deba hacerse necesariamente prescindiendo de cuál sea la mayoría parlamentaria, pero tampoco se dice lo contrario: que por mandato constitucional deba ser tenida en cuenta ${ }^{62}$. En este sentido, la flexibilidad que hasta ahora ha proporcionado el texto constitucional para adaptarse a las cohabitaciones parece que quedaría inalterada con la redacción propuesta, y ello en la medida en que con la nueva dicción del art. 5 la Constitución no estaría facultando al Presidente a apartarse de la mayoría parlamentaria, entre otras cosas porque las propias reglas del parlamentarismo derogarían tal enunciado al menos desde un punto de vista material. En derecho comparado es cierto además que existen fórmulas idénticas o parecidas como en Rusia ${ }^{63}$ o Senegal ${ }^{64}$, cuyos presidentes son elegidos de manera directa. Ahora bien, tal y como han demostrado las distintas cohabitaciones, el Presidente, sin tan siquiera tener título constitucional claro para ello, ha obrado contra los deseos del Gobierno y de la mayoría (negativa a firmar ordenanzas, rechazo a convocatoria de sesiones extraordinarias del Parlamento) y ha pretendido orientar la política exterior y de defensa. Parece de este modo que la

62 Sobre este aspecto, vid. JOSEPH PINI, «Le Premier Ministre, clé de voûte de l'Executif?», Revue française de droit constitutionnel, número hors-série: «Après le comité Balladur. Reviser la Constitution en 2008?», 2008, p. 85.

63 El art. 80.3 de la Constitución de 1993 establece que corresponde al Presidente de la Federación definir las líneas de la política interior y exterior de la Federación, mientras que 110.1 CRus confía el ejercicio del poder Ejecutivo solo al Gobierno correspondiendo a su Presidente en los términos del art. 113 CRus la función de determinar las directrices fundamentales de la acción de gobierno no sólo de acuerdo con la Constitución y las leyes sino también de acuerdo con los decretos del Presidente de la Federación.

64 Según el art. 42.4 el Presidente «determina la política de la Nación» y, de acuerdo con el art. 53.2, el Gobierno «conduce y coordina la política de la Nación».

(C) UNED. Revista de Derecho Político

N. ${ }^{\circ} 81$, mayo-agosto 2011, págs. 199-242 
atribución al Presidente de la definición de la política puede convertirse en munición constitucional para en caso de cohabitación invocar esa función y negar su acuerdo a las normas aprobadas en Consejo de Ministros, en especial las ordenanzas dada la inexistente racionalización del poder reglamentario entre Primer Ministro y Presidente ${ }^{65}$. Sin dicha racionalización y sin un mecanismo de resolución de conflictos entre ambos, no desconocido en otras Constituciones ${ }^{66}$, debe de admitirse que la atribución genérica de la definición de la política está abocada a no aclarar las respectivas funciones en el seno del poder Ejecutivo, como figuraba en el encargo presidencial del estudio de la reforma constitucional, sino a todo lo contrario.

Cabría una última posibilidad para operar una racionalización y clarificación de competencias entre Presidente y Primer Ministro y que no conlleve un riesgo expansivo de la función presidencial de definición de la política para cuando se produzca una cohabitación, pero que el Informe omite. En efecto, si se introdujera una fórmula en el art. 5 CF por la que se vincule de algún modo esa determinación de la política del Presidente a la mayoría existente en la Asamblea o al gobierno, ante una posible cohabitación el Presidente estaría constitucionalmente obligado a adoptar las decisiones de acuerdo con el jefe de la mayoría parlamentaria (el Primer ministro). La fórmula que podría haberse estudiado consistiría en incorporar a la redacción que atribuye al Presidente la definición de la política una cláusula similar a la que contempla la Constitución portuguesa (art. 187.1 CPor) aunque allí es para el caso de la designación del Primer Ministro, que debe llevarse a cabo por el Presidente sobre la base de los resultados electorales de la cámara $/ \mathrm{s}^{67}$. Una sugerencia similar incluía el art. 9 de un proyecto de Constitución para una VI República elaborado en el ámbito académico, pero siempre circunscribiéndola al nombramiento del Primer Ministro, que debería ser designado por el Presidente de la República teniendo en cuenta el resultado de las elecciones legislativas ${ }^{68}$. Definir la política de acuerdo con el re-

65 El rechazo a firmar las ordenanzas del Consejo de Ministros se suele producir ante medidas impopulares forzando entonces el Presidente a adoptar dichas medidas por vía legislativa. Vid. JEAN-MARIE DENQUIN, La monarchie aléatoire, Paris, 2001, p. 86.

66 Así, la Constitución de Finlandia establece en su art. 68 que el Presidente acuerda las decisiones del Consejo de Ministros a propuesta del Gobierno previendo un mecanismo de reexamen en caso de desacuerdo del Jefe del Estado con las propuestas gubernamentales.

${ }^{67}$ Esta previsión ha sido también estudiada en los proyectos de reforma institucional en Italia a partir de la Commissione Bicamerale. Vid. STEFANO CECCANTI, «Il Premierato. Matrici ideali e traduzione nell'oggi», Rassegna Parlamentare, n. 2, Aprile-Giugno, 2003, p. 314.

${ }^{68}$ Citado por Carcassonne, Vid. G. CARCASSONNE, «Les necessités d'un passage...», op. cit., p. 111. 
sultado de las elecciones legislativas produciría ciertamente la adecuación del dictum del actual art. 5 CF a las condiciones de democracia mayoritaria. Pero no se oculta que una fórmula como la que se acaba de describir presenta más de un inconveniente en caso de cohabitación, mientras que en caso de mayorías del mismo partido no incorpora ninguna nueva regla a las que ya rigen por aplicación del sistema parlamentario. En efecto, establecer que el Presidente deba de determinar las políticas de acuerdo con la mayoría en la Asamblea resulta superfluo por cuanto el mecanismo de la censura garantiza por sí solo la aceptación o rechazo parlamentarios de un gobierno ejecutor de las decisiones presidenciales.

Así pues, aun correspondiendo al Presidente la determinación de la política, en el caso de una cohabitación con una mayoría hostil en la Asamblea, la amenaza de censura al Primer Ministro es la garantía más eficaz para imponer una dirección presidencial «parlamentarizada», sin que sea necesario constitucionalizar de modo expreso una función presidencial de determinación de la política que respete el resultado de las elecciones legislativas.

\section{UNA LECTURA DE LA REFORMA EN CLAVE NEOPARLAMENTARIA}

Es menester referirse a la construcción teórica del neoparlamentarismo como formulación escrita y racionalizada del gobierno de Premier para examinar si la evolución institucional reciente de la V República comparte elementos con este modelo.

Uno de los rasgos más salientes del parlamentarismo de Premier es que el cuerpo electoral elige no sólo a una mayoría parlamentaria sino también al Premier, si bien de manera indirecta mediante un mecanismo de «indicación» por el que el partido en las elecciones formalmente parlamentarias presenta no sólo candidatos a ocupar escaños sino que presenta como candidato a Primer Ministro a quien dirige el partido con un proyecto de gobierno. De este modo, no es atrevido afirmar que, aunque sea de manera convencional, el Premier mantiene un doble vínculo fiduciario: con el electorado y con el Parlamento.

Dentro de la clasificación clásica de las formas de gobierno, la de Premier como tal no ha tenido una existencia autónoma ya que había venido siendo estudiada y por tanto teorizada como una especie del genus de la forma de gobierno parlamentaria, teniendo además como referencia el modelo británico, al que una mayoría de países europeos han tratado de emular ${ }^{69}$.

${ }^{69}$ Vid. TOMMASO EDOARDO FROSINI, «La forma di governo del Premierato», Il Filangieri, 2006, p. 133. 
Lo que aquí interesa señalar es que la adaptación de este modelo a otros países europeos con forma de gobierno parlamentaria ha obligado a «codificar» las reglas que en el original son puras convenciones entrelazadas a toda una pluralidad de elementos. Ahora bien, la sola incorporación escrita de las reglas del modelo (elemento formal) no siempre ha satisfecho la expectativa de reproducir el funcionamiento (elemento sustantivo) que ha incentivado su adopción, debido fundamentalmente a elementos extrainstitucionales tales como la estructura del sistema de partidos, el sistema electoral o incluso la falta de idoneidad para construir un grupo parlamentario cohesionado por la disociación entre lo que se ha denominado «partido parlamentario»y «partido electoral» ${ }^{70}$. Es en efecto en experiencias de bajo rendimiento mayoritario donde se han llevado a cabo intentos por reforzar la dirección presidencial del Primer Ministro sobre el Ejecutivo y sobre la mayoría parlamentaria, agrupada y cohesionada en torno a un proyecto político liderado por aquél. La adopción del semipresidencialismo francés estuvo guiado por esta preocupación de reproducir las condiciones del gobierno de Premier solo que estableciendo una diarquía. Frente al modelo francés y como alternativa a éste, el neoparlamentarismo fue teorizado como modelo de extrema racionalización parlamentaria por Duverger, pero cobrando relevancia práctica sólo a partir de la experiencia israelí bajo la Ley fundamental del Gobierno de $1992^{71}$.

Entre las experiencias de democracia parlamentaria de «bajo rendimiento mayoritario» es obligado referirse a Italia, cuya doctrina se interesó por el modelo duvergeriano de neoparlamentarismo como una vía para introducir un gobierno de neo-premier electivo ${ }^{72}$. El gobierno de neo-premier o neoparlamentario se ha introducido por el momento en Italia en el ámbito regional (tras la ley constitucional núm. 1 de 1999) y local (ley constitucional núm. 81 de 1993) e igualmente se ha pretendido adoptar para la forma de gobierno republicana en di-

70 Distinción acuñada por Leopoldo Elia y recogida por Manzella. Vid. ANDREA MANZELLA, «Partiti politici e forme di governo nell'Unione europea», Il Mulino. Rivista bimestrale di cultura e di politica, n.1, enero-febrero, 2008, p. 135.

71 Vid. MARCO OLIVETTI, «L'elezione diretta del Primo Ministro e la teoria delle forme di governo», Studi parlamentari e di politica costituzionale, n. 116, $2^{\circ}$ Trimestre, 1997, p. 60. Vid. también STEFANO CECCANTI, «Il modello neo-parlamentare, genesi e sviluppi», en AA.VV. Scrtti in onore di Serio Galeotti, Milano, 1998, Tomo I, pp. 183 y ss.

72 Sobre dichas reflexiones doctrinales, que se han extendido varias décadas a partir de 1963, vid. FRANCESCO CLEMENTI, «Il Governo del Primo Ministro: Da Londra (via Parigi) a Roma, possibilmente senza pasarse per Tel Aviv, en STEFANO CECCANTI e SALVATORE VASALLO, Come chiudere la transizione. Cambiamiento, apprendimento e adattamento nel sistema politico italiano, Bologna, 2004, en especial, pp. 297-298. 
versas ocasiones, primero para impedir que la mayoría parlamentaria surgida de las urnas sufra alteraciones y que el Ejecutivo dependa de la mediación de los partidos, y de manera más reciente, para llevar a reglas escritas la praxis del bipolarismo mayoritario de partidos alcanzado solo después de la reforma electoral de $1993^{73}$. Lo que importa subrayar ahora no son sin embargo los fines del modelo neoparlamentario (local y regional) italiano, sino los elementos semipresidenciales, que al decir de cierta doctrina contiene este modelo basándose en que articula una elección separada del Premier y el Parlamento. Esta posición doctrinal tiene además cierta coherencia si se acoge la tesis de que el semipresidencialismo debe ser considerado una variante de la forma de gobierno parlamentaria ${ }^{74}$. Téngase en cuenta que incluso a partir de rasgos no tan evidentes de semipresidencialismo se ha defendido en España la asimilación, si no su inclusión dentro de la forma de gobierno semipresidencial, de los sistemas de gobierno autonómicos, donde no existen, como en Italia, elecciones separadas para elegir jefe del ejecutivo y órgano parlamentario. Esta adscripción ha sido empero desmontada poniendo de manifiesto que en la forma de gobierno autonómica contenida en algunos Estatutos se echan en falta dos elementos estructurales del presidencialismo: de una parte la diarquía dentro del poder Ejecutivo, y de otra la elección directa por sufragio del Presidente diferenciada de la elección parlamentaria. Así por ejemplo, respecto al primero de ellos Gerardo Ruiz-Rico entiende que la ausencia de dualismo de los Ejecutivos autonómicos hace que no exista «posibilidad alguna de ruptura del principio monocrático como criterio de configuración del Ejecutivo regional» ${ }^{75}$. Tampoco se da — siempre según el mismo autor-el segundo elemento «ya que el sistema de designación del máximo representante de la Comunidad Autónoma —elección por el Parlamento autonómico- evita siempre la posible creación de dos mayorías (la gubernamental y la presidencial) que tienen que "cohabitar" ${ }^{76}$. Este enfoque tiene un carácter funcional al asociar

73 Tales tentativas tuvieron comienzo con el denominado «decálogo Spadolini» en 1982, al que siguieron las propuestas de reforma de la Comisión Bozzi (1983), De Mita-Iotti (1983), la Comisión bicameral D’Alema (1997) y el referéndum de reforma constitucional de 2006.

74 Vid. omnibus, FULCO LANCHESTER, Gli strumenti della democrazia, Milano, 2004, p. 106 para quien se dan en el semipresidencialismo dacultad de disolución, refrendo de actos presidenciales y procesos de retirada de la confianza. En contra, vid. STEFANO MERLINI, «La forma di governo: I poteri del Presidente della Repubblica», en PAOLO CARETTI (a cura di), La riforma della Costituzione nel progetto della Bicamerale, Padova, 1998, p. 40.

75 Vid. GERARDO RUIZ-RICO RUIZ, «La forma de gobierno autonómica en España», en GERARDO RUIZ-RICO RUIZ Y SILVIO GAMBINO, Formas de gobierno y sistemas electorales (la experiencia italiana y española), Valencia, 1997, p. 534.

76 Ibid., p. 535.

(C) UNED. Revista de Derecho Político 
los dos elementos estructurales que venimos comentando a sus consecuencias: Ejecutivo monocrático y dualidad de mayorías. Interesa señalar al respecto que estos mismos argumentos, que han servido para marcar las líneas de separación entre regímenes parlamentarios (autonómicos) y semipresidencialismo, son los que ahora y especialmente tras las reformas del bienio 2000-01 sustentan la posición de quienes constatan una evolución o incluso una mutación de la forma de gobierno en Francia hacia el neoparlamentarismo. En efecto, después de la reforma del quinquenato y la inversión del calendario electoral se habría dado con el mecanismo que permite hacer coincidir mayoría presidencial y mayoría parlamentaria convirtiendo en marginal la hipótesis de una cohabitación.

Del mismo modo, la equiparación del mandato presidencial a la duración de la Legislatura proporcionaría una configuración monocrática del Poder Ejecutivo al consolidar la función presidencial como función de gobierno. En este sentido, las reformas del quinquenato y la de inversión del calendario electoral habrían sentado las bases funcionales para consolidar una forma de gobierno de dirección presidencial de carácter monista ${ }^{77}$, ya que especialmente a través del mecanismo de la elección casi contextual de elecciones presidenciales y legislativas puede pensarse que en la práctica se ha institucionalizado la coincidencia de mayoría presidencial y mayoría parlamentaria. No resulta intrascendente a este respecto que el mayor énfasis para desestimar el semipresidencialismo francés como forma parlamentaria de gobierno se haya puesto en la falta de uno de sus caracteres esenciales como es el monismo de la representación política. Tras las mencionadas reformas se habría, pues, avanzado hacia una monocracia de Premier más que hacia la monocracia del presidencialismo americano, y ello en virtud del poder de disolución parlamentaria del Presidente de la República, potestad contra la que además no existe en la V República un contrapeso institucional. Sin embargo, esa ausencia de un contrapeso a la potestad discrecional de disolución no es óbice para parangonar el monismo del semipresidencialismo francés al de un gobierno de Premier: al contrario, ha servido para señalar que el desuso efectivo en el que ha caído el mecanismo de la moción de censura como contrapeso a la facultad de disolución en las formas de gobierno de Premier no hace tan diferente su status a la irresponsabilidad del Presidente francés ${ }^{78}$. Ahora bien, esa convergencia del Presidente

77 En concordancia con la definición de Duverger, que define esta forma de gobierno como un «monismo mayoritario de hegemonía del Jefe del Estado». Vid. MAURICE DUVERGER, Le système politique français, Paris, 1996, p. 532.

78 También a la inversa, la irresponsabilidad política del Primer ministro que se da en la práctica en el gobierno de premier dotaría a éste de un status parecido al del Presidente en la V República. A este respecto, Leopoldo Elia indicaba que «la invulnerabilidad para toda la Legislatura 
con el status de Premier es relativa si se considera la facultad de disolución, ya que en las nuevas condiciones impuestas por el quinquenato es improbable que el Presidente se aventure a hacer uso de la disolución anticipada, a sabiendas no sólo de que con ello puede dar lugar a una nueva cohabitación, sino de que estaría alterando el calendario electoral, derogando las elecciones contextuales a Presidencia y Asamblea, lo cual viene a ser una de las fragilidades de la pretendida evolución funcional de la V República hacia un régimen de neo-premier.

En todo caso el paralelismo que tras la reforma del quinquenato se ha tratado de establecer a nivel funcional con el gobierno neoparlamentario de premier, habría servido al legislador de la reforma de 2008 para dotar a la irresponsabilidad política del Presidente de contrapesos que vienen a coincidir con los mismos correctivos que contrarrestan el monocratismo en los regímenes parlamentarios de dirección presidencial ${ }^{79}$, tales como el reconocimiento de un estatuto de la oposición (art. 51-1 CF $)^{80}$, del que se ha constitucionalizado alguna manifestación como la garantía de una sesión de control parlamentario de las minorías o la presidencia de comisiones. Como es sabido, el estatuto de la oposición es el contrapeso material necesario en los sistemas de parlamentarismo mayoritario en los que orden constitucional sigue contradictoriamente aferrado a dualismos inexistentes, dado que los equilibrios institucionales formales concebidos a partir del dualismo Ejecutivo-Parlamento han sido sustancialmente alterados y reemplazados por los nuevos equilibrios entre partido-gobierno y oposición dentro exclusivamente del órgano parlamentario ${ }^{81}$. Declarado en su día inconstitucional al incorporarse por la vía del Reglamento parlamentario ${ }^{82}$, la consti-

de un primer ministro dotado de poderes exorbitantes en un régimen de práctica irresponsabilidad política», con la que se trató de introducir el modelo de Premier forte en el referéndum de reforma constitucional italiana de 2006, era un modo de perseguir los mismos objetivos que la reforma del quinquenato y del calendario electoral en Francia. Vid. LEOPOLDO ELIA, «La forma di governo», en MAURIZIO FIORAVANTI, (a cura di), Il valore della Costituzione. L'esperienza della democrazia repubblicana, Bari, 2009, p. 72 (cursiva nuestra).

79 Así por ejemplo la constitucionalización de un estatuto de la oposición ha sido reclamada en nuestra doctrina por Garrorena, vid. MIGUEL ÁNGEL GARRORENA, Rerpresentación política y Constitución democrática, Madrid, 1991, p. 89. En cuanto a la limitación en nombramientos dependientes del Gobierno, vid. E. VIRGALA FORURIA, «La forma de gobierno semiparlamentaria...», op. cit., p. 119.

${ }^{80}$ En este sentido por ejemplo, vid. MAURO VOLPI, «Natura e prospettive della V Repubblica Francese», Politica del Diritto, a. XXVIII, n. 4, dicembre 1997, p. 578.

${ }^{81}$ Vid. JOSÉ ANTONIO MONTILLA MARTOS, Minoría política y Tribunal Constitucional, Madrid, 2002, p. 101.

${ }^{82}$ Décision 2006-537 DC, de 22 junio de 2006, «Résolution modifiant le règlement de l'Assemblée Nationale».

(C) UNED. Revista de Derecho Político 
tucionalización del estatuto de la oposición sitúa la Constitución francesa a la vanguardia del constitucionalismo europeo, además de introducir uno de los equilibrios que repetidamente se había venido solicitando en sede doctrinal ${ }^{83}$.

\section{CONCLUSIONES}

Es indudable que el monocratismo que en su actual configuración funcional ha recibido la forma de gobierno francesa no ha sido constitucionalizado, si bien el Comité de Reflexión apuntaba a esa solución. Expresión de un gobierno monocrático nos parece no obstante la previsión de dirigir discursos al Parlamento. Cabe citar a este respecto que el proyecto de reforma constitucional italiano de 2006, y por el que se pretendía constitucionalizar una forma de gobierno de «Premier fuerte», recogía la obligación del Primer Ministro de presentar a las cámaras un informe anual sobre la actuación del programa de gobierno y del estado del país. No acaban ahí las similitudes de las propuestas del Comité Balladur con el proyecto sometido a referéndum en Italia, puesto que en él se hacía expresa atribución constitucional al Premier de la función de determinar la política general y que va más allá de la tradicional función de gobierno o de dirección de la política.

Puede por tanto, a tenor de lo que se acaba de exponer, aceptarse que las reformas sobre el quinquenato y el calendario electoral hayan supuesto un afianzamiento en sentido monocrático de la forma de gobierno, y puede igualmente admitirse que la revisión constitucional de 2008 ha supuesto completar esta evolución introduciendo los contrapesos necesarios inspirados en el gobierno de Premier, pero ello no impide que puedan formularse objeciones de cierto calado en torno a la supuesta mutación de la $\mathrm{V}$ República en un régimen de neo-premier. La principal objeción es que aun cuando el tándem de elecciones presidencialeslegislativas intenta trasplantar la lógica del modelo neoparlamentario en el que la elección a Premier y cámara legislativa técnicamente es una elección combinada, sin embargo no puede decirse que las presidenciales y legislativas en Francia tengan por el momento ese mismo carácter. No lo tienen porque aunque funcionalmente puedan tener el sentido de una elección combinada, estructuralmente no lo son. La explicación es que para poder ser considerada una elección combinada, cualquier causa que motive un cese anticipado en el mandato del premier-presidente o de los parlamentarios, debe imponer una nueva convoca-

83 Vid. LOÏC PHILIP, «Pour une rasionalitation des pouvoirs dans le cadre des institutions de la $V^{e}$ République», en AA.VV., Constitutions et pouvoirs, op. cit., p. 429. 
toria electoral en virtud de la regla simul stabunt simul cadent en cuya virtud queda asegurado que ante cualquier circunstancia que haga finalizar anticipadamente el mandato presidencial o de los diputados, Presidente y parlamentarios vuelvan a ser elegidos de forma simultánea o contextual. Para ello no bastaría, como el Comité Balladur parecía sugerir, hacer coincidir elecciones presidenciales y legislativas de manera plena ${ }^{84}$. Ni tampoco hubiera bastado una solución como la estudiada (aunque descartada) por el Comité, consistente en imponer la disolución automática de la Asamblea Nacional en caso de dimisión, fallecimiento o impedimento permanente del Presidente, situación en la cual el actual art. 7 CF impone convocar elecciones presidenciales. La razón es que hubiera supuesto una trasposición incompleta de la regla «simul simul», ya que debería haber sido prevista la dimisión presidencial para el supuesto de disolución anticipada y también la disolución automática y la dimisión del Presidente para el caso de una moción de censura adoptada y votada contra el Primer Ministro ${ }^{85}$.

Así pues, resulta evidente que los cambios introducidos desde 2000 no son suficientes para definir el régimen semipresidencial francés conforme al modelo de neopremier descrito. La idea que lo vertebra es que toda alteración, ya sea en la mayoría parlamentaria elegida por los votantes o en la permanencia del Premier directamente elegido, debe conducir a un nuevo proceso electoral. Todo cambio en la relación Parlamento-Ejecutivo exige la convocatoria de elecciones en ambas instituciones. De esta manera se logra que el jefe del Ejecutivo reciba el mandato de gobierno directamente del electorado, lo que implica que no puede ser reemplazado por un simple cambio en la composición de la mayoría (especialmente en el caso de coaliciones de gobierno), ni tampoco por un candidato impuesto por una mayoría opositora mediante moción de censura (porque en el modelo neoparlamentario se recurre a las urnas de nuevo).

Debe añadirse además que la mayoría se beneficia de la elección del Premier, al menos en el modelo italiano por llevar aparejada un premio en escaños adicionales. Desde este punto de vista puede afirmarse que en el modelo de neopremier la mayoría lo es gracias a la elección del Premier y, viceversa, que el Premier ha sido elegido como tal por los votos que han apoyado su partido. La expresión más evidente de ello es la inclusión en una misma papeleta electoral del nombre del candidato a Premier junto a la lista de candidatos a parlamentarios del partido, lo que constituye por otra parte el grado más alto de simulta-

${ }^{84}$ Vid. MAURO VOLPI, «La forma di governo in Francia alla luce della riforma costituzionale del luglio 2008», Relazione en el Seminario de Astrid «La riforma della Costituzione in Francia», Roma, 19 de noviembre de 2008, p. 18 (existe versión on-line).

${ }^{85}$ Vid. M. VOLPI, «La forma di governo in Francia...», op. cit., p. 21. 
neidad de elección directa. Este principio en virtud del cual la mayoría parlamentaria debe su existencia no tanto o no solo a los votos recibidos en las elecciones legislativas, sino al hecho de que pertenece al mismo partido que el Premier, constituye el núcleo fundamental de la regla «simul simul». De él se deriva que la mayoría debe subsistir mientras también lo haga el Premier a cuya elección la mayoría debe su existencia. Ello no es sino una traslación de la regla no escrita del parlamentarismo de premier con arreglo a la cual por convención se entiende que el líder del partido, o el cabeza de lista por una determinada circunscripción, está «indicado» como candidato a Primer Ministro. En este sentido cabe objetar que aunque el Premier sea elegido de forma separada pero simultánea al Parlamento, dicha coincidencia de procesos electorales no es, como ha apuntado más de un autor, un mecanismo garantizador de esa causalidad entre la elección del Premier y la obtención de la mayoría parlamentaria. No obstante debe reconocerse que aun no asegurando mayoría de escaños al partido del Premier a través de un premio de mayoría, la proximidad o coincidencia de ambas elecciones sientan las bases para que mediante convenciones se supla la falta de dicho elemento estructural, situación a la que parece apuntar Francia. En efecto, considerado de este modo, la precedencia y proximidad entre elecciones presidenciales y legislativas incentivan que se instaure una convención por la cual el voto de los electores puede materialmente convertirse en la elección del jefe del ejecutivo dentro de un sistema semiparlamentario en el que la elección del Presidente supone la elección del líder de la mayoría parlamentaria y que por congruencia con el denominado «gobierno de partido» llevará al electorado a otorgar la mayoría al partido presidencial. Sin embargo hemos dicho que es esencial a la regla «simul simul» el que la mayoría parlamentaria debe su existencia a la elección del Premier (Presidente en el caso francés) entablándose un nexo causal que no debe perderse durante toda la legislatura. Consciente de ello el Comité Balladur estudió la posibilidad de introducir la regla «simul simul» imponiendo al Presidente de la República su dimisión cuando en elecciones legislativas separadas de las presidenciales provocadas por una disolución anticipada de la Asamblea Nacional, el Presidente perdiera la mayoría parlamentaria ${ }^{86}$. Tal posibilidad fue sin embargo finalmente descartada por encontrar difícil acomodo en la Constitución.

Así pues, para algunos autores, la inversión del calendario y la contigüidad de las elecciones presidenciales con las legislativas no cabe interpretarlas como una aproximación funcional al modelo de neopremier sino una deriva hacia lo que

86 Cfr. Une Vee République plus démocratique, p. 30. 
Volpi denomina una Presidencia de legislatura ${ }^{87}$, producto de un resultado electoral, pero no producto de la aplicación de la regla simul stabunt que en buena lógica debería obligar a unir la renovación de mandatos a la presidencia y a la Asamblea.

Ahora bien, frente a estas tesis se ha advertido que es en cambio posible constatar una evolución institucional de la V República hacia el neoparlamentarismo, quizás porque el propio semipresidencialismo lo es para cierta corriente doctrinal. Afirmar que se da esta evolución o mutación en la dirección de un gobierno de neopremier no puede tener más significado según sus defensores que el de constatar un cambio de tendencia sin que en ningún caso ello pueda ser tomado como un intento por redefinir o inscribir el semipresidencialismo francés dentro del modelo neoparlamentario. Quien probablemente ha insistido más en esta línea haya sido Ceccanti, quien subraya la importancia de la coincidencia de duración de mandatos (presidencial y de la cámara baja) y la limitación a una sola reelección como elementos que se encontraban presentes en la elaboración duvergeriana del modelo de neoparlamentarismo ${ }^{88}$. El autor precisa además que la evolución institucional tras las reformas de 2000 (ley constitucional sobre el quinquenato) y de 2001 (ley orgánica de inversión del calendario electoral) a la que viene a sumarse la de julio de 2008, admiten dos lecturas que no son a su juicio contradictorias entre sí: la de un presidencialismo anómalo (por seguir existiendo una doble convocatoria electoral no coincidente que afecta al Ejecutivo, por la permanencia del Primer Ministro) y la de un neoparlamentarismo con el Presidente como una suerte de superpremier ${ }^{89}$ (misma duración del mandato para Presidente y Asamblea, porque la duración máxima del mandato parlamentario depende de la elección presidencial $)^{90}$. La evolución seguida sugiere a Ceccanti una lectura en clave de monismo mayoritario: la elección presidencial versa sobre un programa para cuya actuación se dota al Presidente de los medios legislativos adecuados a través de las elecciones a la Asamblea ${ }^{91}$. En este sentido la inversión del calendario electoral (presidenciales y legislativas) y la coincidencia de mandatos señalarían para el autor un paso que marca aún más la evolución hacia el afianzamiento de la posición constitucional del Presidente como jefe del Ejecutivo,

87 Ibid., p. 21.

88 Vid. STEFANO CECCANTI, «Francia: Breve replica a Mauro Volpi sulla revisione francese», en Forum di quaderni costituzionali, 15 de octubre de 2008.

89 Vid. STEFANO CECCANTI, «La Quinta Repubblica: Un lento (e parziale) avvicinamento alle altre forme di governo europee», en DOMINIQUE ROUSSEAU (a cura di), L'ordinamento costituzionale della Quinta Repubblica francese, Torino, 2000, p. 22.

90 Vid. S. CECCANTI, «Francia: Breve replica...», op. cit.

91 Ibid.

(C) UNED. Revista de Derecho Político 
abandonando de esta suerte la ambigüedad de su configuración anterior, desvelándose ahora y por decirlo de algún modo su posición de cabeza del Ejecutivo.

No se puede objetar por consiguiente que la reducción del mandato presidencial y la inversión del calendario electoral han creado las condiciones para que se produzca una «Presidencia de legislatura». Pero, al mismo tiempo, el vínculo fiduciario que caracteriza las relaciones entre Ejecutivo y Legislativo en los sistemas parlamentarios no permite identificar desde luego al Presidente con un Premier sujeto a la confianza parlamentaria. Solo si se trasciende el plano estructural y orgánico y se adopta una perspectiva teleológica y causal es posible anotar una serie de afinidades entre el llamado neoparlamentarismo o parlamentarismo de Primer Ministro electivo y la actual tendencia a la que parece apuntar el (semi)presidencialismo francés. Así, la relación causal del pueblo con las instituciones de gobierno es en ambos casos directa o inmediata y asimismo en ambos diseños se tiende a debilitar la intermediación de los partidos como fuente de legitimidad tanto del Gobierno como del Premier o Presidente del Consejo de Ministros (en el caso francés).

En fin, el rendimiento de la forma parlamentaria de gobierno, entendida como democracia de mandato electoral de gobierno, parece que viene a ser el medidor de su correcto funcionamiento, en el que la gobernabilidad y estabilidad parlamentaria ocupan un lugar central ${ }^{92}$. En este aspecto, que trata de adecuar los equilibrios a un rendimiento estable y consonante con el mandato electoral, es en el que puede ciertamente hallarse un paralelismo en la evolución de la V República hacia técnicas institucionales próximas a los sistemas de neopremier. Ello implica admitir que el favorecimiento de una mayoría del partido presidencial en la cámara del gobierno durante su mandato conforma una presidencia de legislatura que no elimina el dualismo en el Ejecutivo, si bien se aproxima funcionalmente al sistema parlamentario. Pero no cabe duda que la actual estructura institucional impide aplicar la regla «simul stabunt simul cadent», que debería imponer el recurso a la doble elección del jefe del Ejecutivo y de la cámara baja cuando se produce una ruptura del vínculo fiduciario con el Gobierno, o cuando se recurre anticipadamente a la disolución de la asamblea parlamentaria en base a la unicidad que liga el mandato electoral del Premier al de los diputados. Así pues, aun revestido de los atributos de un jefe de gobierno parlamentario, la institución del Presidente de la República francesa debería vincular la duración de su mandato a las vicisitudes del

92 Así lo admite también la doctrina española para la forma de gobierno contenida en nuestra Constitución, vid. EDUARDO VIRGALA FORURIA, «La forma de gobierno semiparlamentaria como alternativa a la presidencial y a la parlamentaria», en Revista de Estudios Políticos, n. 89, julioseptiembre, 1995 , p. 119. 
mandato de los parlamentarios y viceversa, para poder realmente adoptar técnicas que orientaran la forma de gobierno semi-presidencial hacia los principios que guían el parlamentarismo de neo-premier.

\title{
Title
}

«The Evolution of French System of Government: A Pathway towards a neoparlamentarian presidentialism?»

\section{Summary}

I. Introduction. II. The debate on a mutation in system of government. III. The possibility of an institutional control over the President. A) The right to address messages and speeches to the Houses of Parliament. B) The attendance of the President at investigation committees. IV. The problem of delimitation of functions between President and Prime Minister: The function of governing. V. A read of the reform from a neo-parlamentarian view. VI. Conclusions.

\section{Resumen}

En torno a la reforma constitucional francesa de 2008 existe un cierto consenso en cuanto a que ha supuesto un paso más en la evolución iniciada en el bienio 2000-01 con la reforma del quinquenato y la inversión de elecciones, y en cuanto a que viene a significar el inicio del fin del debate en torno a una VI República. Sin embargo sigue sin haber acuerdo respecto a si esta reforma acentúa el carácter hiperpresidencialista de la V República con la consolidación de una presidencia de legislatura, o si por el contrario existen elementos funcionales no muy diferentes a los de un neoparlamentarismo de investidura electiva.

Aunque resulte cierto que en el plano estructural no sea posible afirmar que las recientes reformas permitan definir la forma de gobierno francesa tomando como referente el modelo neoparlamentario, no resulta del todo inútil examinar esta reciente evolución a partir de la finalidad que ha animado este proceso reformador. La razón es que en sus criterios inspiradores sí cabe apuntar ciertas semejanzas en la reciente evolución institucional de la V República con los fines que con el modelo neoparlamentario pretende perseguir, en particular, el rendimiento mayoritario de las instituciones.

\begin{abstract}
There is some consensus that revision on 2008 of French Constitution was a step in the evolution that began in the 2000-01 biennium with the quinquennat reform and the calendar inversion of elections, and
\end{abstract}


that it comes to mean the beginning of the end of the debate around a Sixth Republic. But there is still no agreement on whether this reform accentuates the byperpresidentialist character of the V Republic, with the consolidation of a "presidency of legislature», or if instead there are functional cleavages not unlike those of a neo-parliamentarism of elective investiture.

Although from a structural point of view recent reforms doesn't allow to define the French government taking the neoparlamentarian model as referent, a view from the purposes that had motivated the reform process then maybe useful. The reason is that there are certain similarities in the recent institutional evolution of the $\mathrm{V}$ Republic with the aims of neoparlamentarin model, more specifically, the majoritarian performance of institutions.

\section{Palabras clave}

Quinta República francesa, reforma constitucional, modelo neoparlamentario, semipresidencialismo, jefe de Estado.

\section{Key words}

Fifth French Republic, constitutional reform, neoparlamentarian model, semipresidentialism, Head of state. 